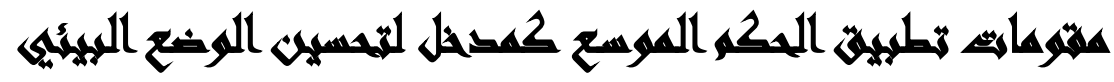

\section{هي}

\section{[1 r ]}

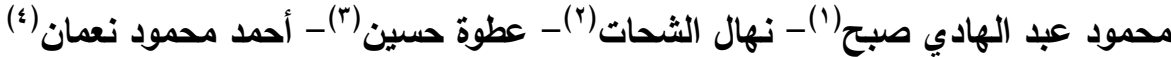

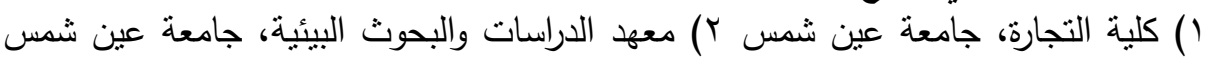

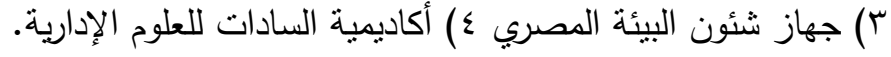

\section{المستخليك}

هدف البحث إلى دراسة مفهوم الحكم الموسع، والحوكمة البيئية وأبعاده ومقوماته وتحليل

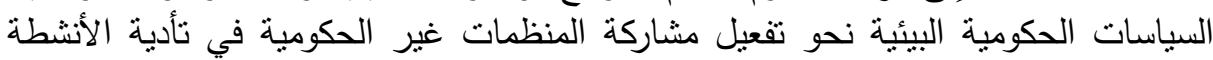
البيئية وعرض تطور دور الدولة في تأدية النشاط البيئي ومدى جودة الأنشطة البيئية بالتركيز على محافظة القاهرة.

واستخدم الباحث المنهج الوصفي التحليلي لهذا الغرض واستخدم قائمة الاستقصاء كأداة

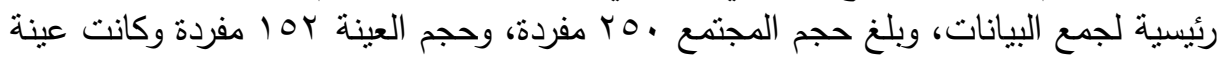
Statistical Package for Social ) عشوائية وتم استخدام حزمة البرامج الإحصائية نوانية SPSS (Science

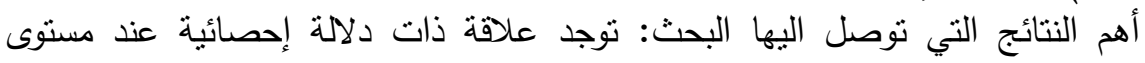

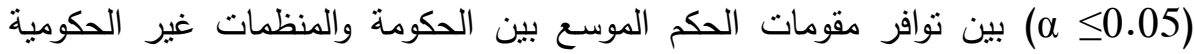

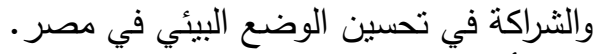
أهم التوصيات التي قدمها البحث: خلصت التين الدراسة إلى تقديم عدة توصيات لتطبيق

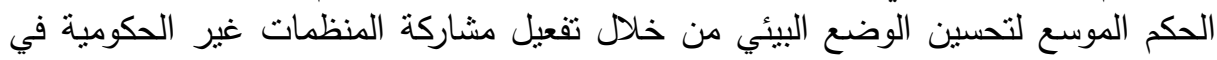

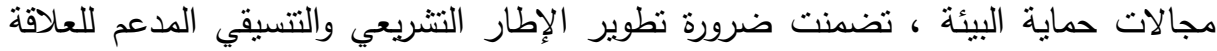

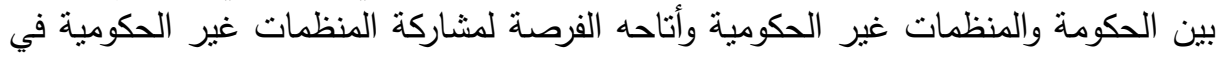

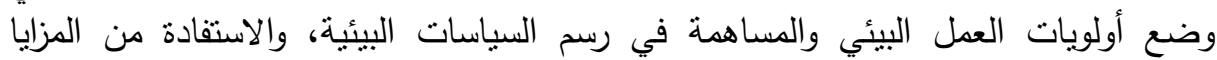
النسبية للمنظمات غير الحكومية وضرورة تقنين الوضع التمويلي للمنظمات غير العير الحكومية وتتظيم العلاقة الإترافية على التمويل الأجنبي للمنظمات غير الحكومية. 


\section{المهابs}

أدت العديد من التغيرات الدولية والإقليمية إلى حتمية التغيير في دور الدولة وإعادة صياغة دورها في خدمة المجتمع، فلقد أدت تغيرات مثل العولمة والاتفاقيات الدولية والتطور

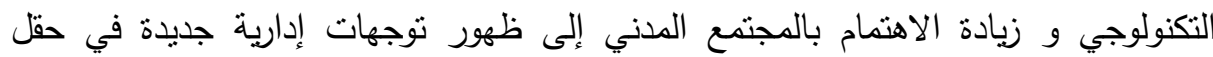

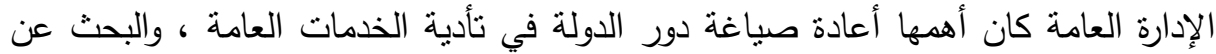
شركاء للوزارات والهيئات العامة في تأدية الأنشطة الخدمية العامة، وبمعنى أكثر تحديدا حوكمة النشاط العام وإيجاد شراكة بين الحكومة والمجتمع المدني في تقديم الخدمات العامة، ويتضمن التوجه نحو الحوكمة العديد من المداخل لتحسين أداء الجهاز الحكومي.

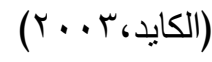

وبالرغم من أتفاق المبادرات المتزايدة للحوكمة والثراكة بين الحكومة والمنظمات غير الحكومية على المستوى العالمي في كونها تفاعل بناء في تأدية النشاط العام من خلال الدعم

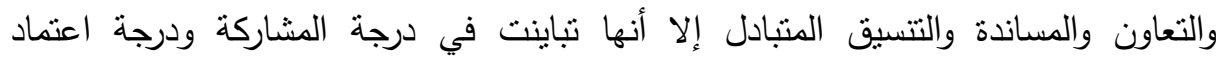

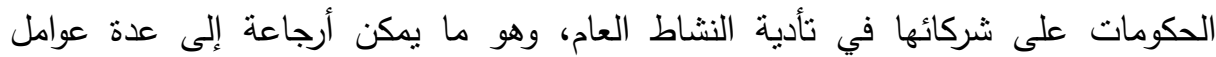
(UNDP, 2003) اعتبارها شريك الحكومة في تتفيذ خطط التتمية، بالإضافة إلى القيم والمبادئ الإدارية الخاصة

$$
\text { بكل دولة. }
$$

ولقد برز مفهوم الحكم الموسع أو الشراكة أو الحكم الجيد أو الحكم الرشيد أو إدارة شئون

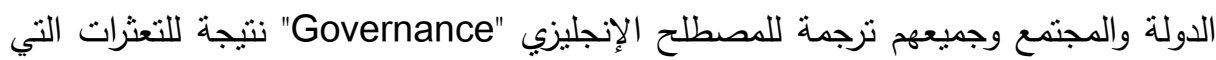
واجهت الدول الاشتراكية ذات التخطيط المركزي في الوقت الذي استطاعت فيه الدئ الدول الرأسمالية تحقيق نجاحات عديدة اعتمادا على القطاعين الخاص والأهلي، وحل مصطلح

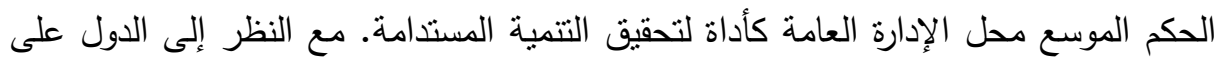

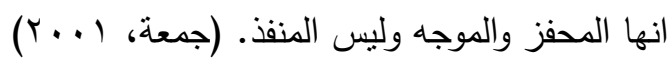


وقد طرح مفهوم الحوكمة البيئية Environmental Governance في بداية

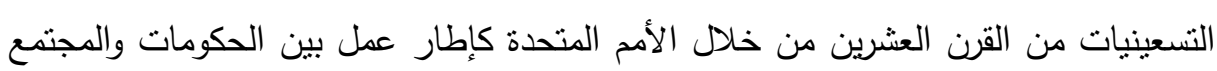

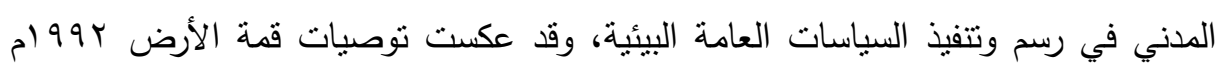
مدي الاهنمام بالمنظمات غير الحكومية كشريك للحكومات في قضايا البيئة واعتبارها اليد السحرية للحكومات في تحسين الوضع البيئي من خلالها. ولقد أدركت وزارة الدولة لشئون

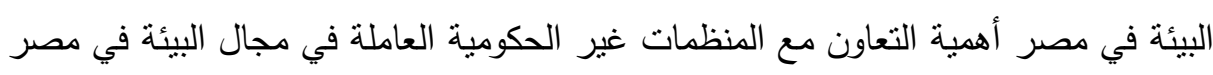

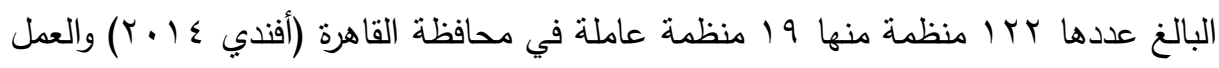
على بناء قدراتها وتعزيز مجالات التعاون معها إيمانا بمقدرتها على تتفيذ المشروعات البيئية

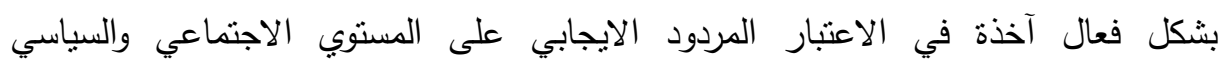
والاقتصادي لهذه الشراكات. وفى هذا الإطار فإن الدراسة الحالية عملت على دراسة وتطبيق مفهوم ومقومات الحكم

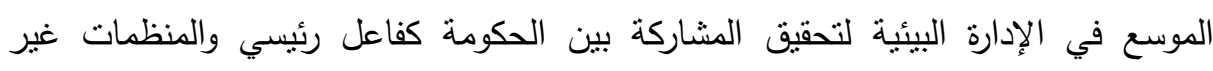
الحكومية في تأدية الأنشطة البيئية، وبحيث عملت الدراسة على تحديد مقومات تطبيق الحكم

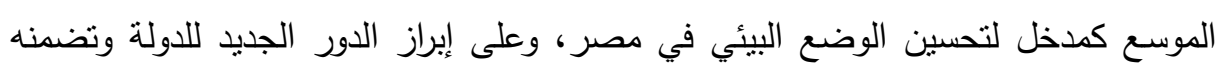
إلى الحكم الموسع كمدخل لتحسين الجودة في الجهاز الحكومي وتحسين مخرجاته.

\section{Xis}

تعتبر الأنشطة البيئية من أهم الأنشطة التي لا يمكن التقصير فيها، لارتباطها المباشر

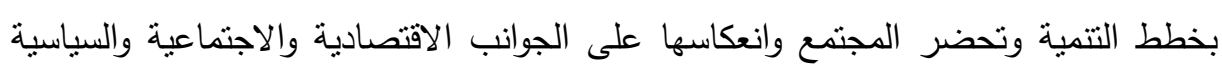

للاولة.

وقد أظهرت الدراسة الاستطلاعية التي قام بها الباحث واعتمدت على المقابلات الثخصية مع عينة من مسئولي المنظمات غير الحكومية العاملة في مجال حماية البيئة

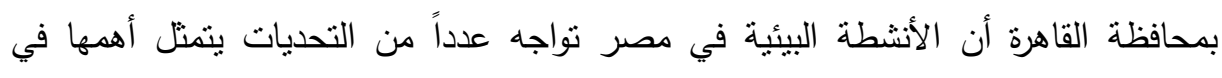
نقص الموارد الحكومية وعدم القرة على التوسع في تأدية النشاط العام ذو الطلب المتزايد كماً وكيفاً.

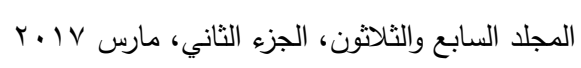


وتتحدد المشكلة في الضغوط المجتمعية المحلية المطالبة بتحسين مخرجات الأنشطة

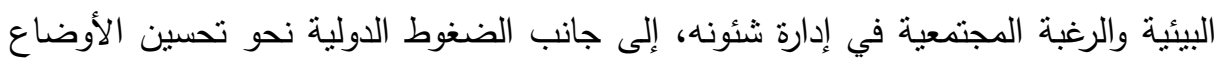

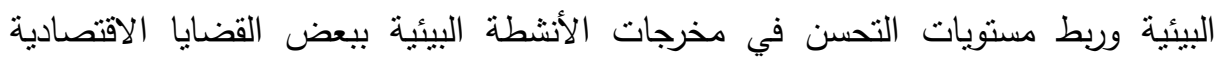
والسياسية.

وبالتالي فقد بات من الأهمية البحث عن شركاء للحكومة لديهم القدرة على المساهمة في تحسين جودة الأداء الحكومي من خلال مشاركتهم في رسم السياسات العامة والمشاركة في تأدية الأنشطة البيئية.

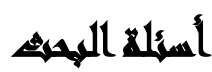

عملت الدراسة على الإجابة على ثلاثة أسئلة هي: ا. ما مدى إدراك المنظمات غير الحكومية لمفهوم ومزايا الحكم الموسع في تحسين الوضع لدابه

r. ما هي اشكال الثراكة بين الحكومة والمنظمات غير الحكومية في تحسين الوضع البيئي؟

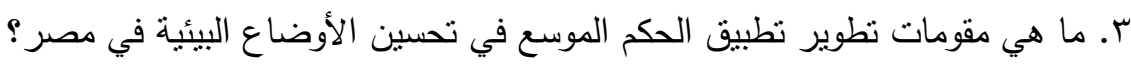

\section{أهمية القواسمة}

ا-الأهمية العلمية: تستمد الدراسة أهميتها العلمية من حداثة موضوع الحكم الموسع في

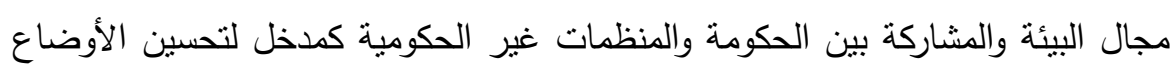
البيئية في مصر تحديداً، حيث لم تهتم الأدبيات العربية بدراسة مفهوم وأبعاد عملية الحكم الموسع وربطها بتحسين أداء المنظمات العامة وبخاصة في قطاع البيئة. r -الأهمية العملية: نمثل أنشطة حماية البيئة وتحسين الأوضاع البيئية أحد أهم أنشطة الإدارة العامة وذلك لكون الوضع البيئي الركيزة الأساسية لعملية التتمية الحضارية

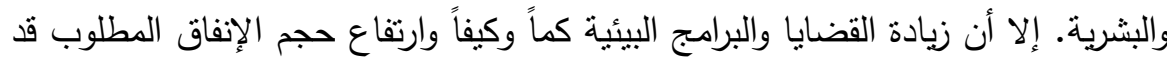

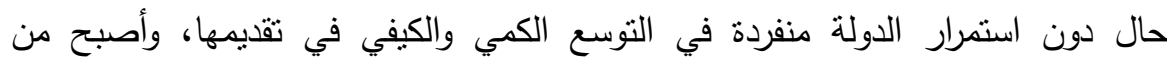


الضرورة البحث عن شركاء للحكومة لديهم القدرة على المشاركة في تقديمها. وفى هذا

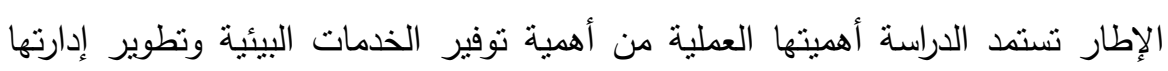

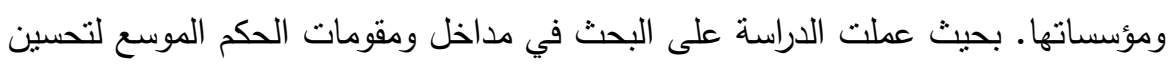
أداء الجهاز الحكومي القائم على تقديم الخدمات البيئية وتحليل المعوقات التي تواجهها، بلهي مع دراسة الأدوار المقترحة للمنظمات غير الحكومية للمشاركة في تقديم الأنشطة البيئية.

\section{أهساهية الصواسها}

عملت الاراسة على تحقيق الأهداف التالية: 1-براسة مفهوم الحكم الموسع، والحوكمة البيئية وأبعاده ومقوماته. r-دراسة مقومات تطبيق الحكم الموسع كمدخل لتحسين الوضع البيئي في مصر ورس البعاده r-دراسة آراء مسئولي المنظمات غير الحكومية العاملة في مجال البيئة في محافظة القاهرة

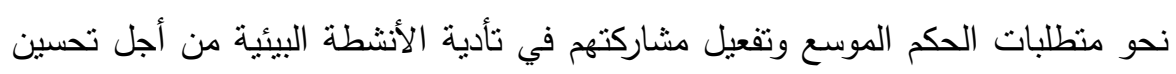
الأوضاع البيئية في مصر منابن

\section{هزغية القواسمة}

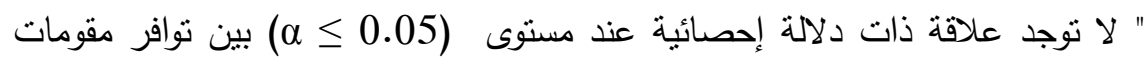
الحكم الموسع بين الحكومة والمنظمات غير الحكومية والثراكة في تحسين الوضع البيئي في مصر."

\section{السراسايت الساريهة}

قام الباحث بمراجعة الأدبيات والبحوث السابقة التي اهتمت بتطوير المؤسسات العامة

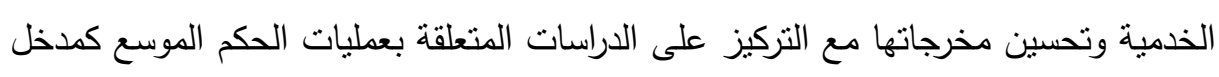

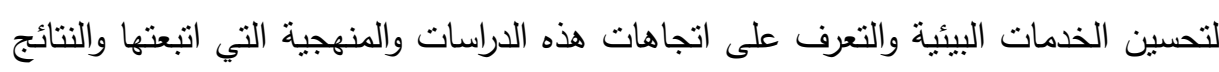

الني توصلت إليها. 
وأوضحت دراسة (جمعة، ا + . Y ) أن مفهوم الحكم الموسع Governance يدور حول عدة محاور تتمثل في دولة الحد الأدنى وتعنى عدم تدخل الدولة في تقديم الخدمات العامة وتركها لآليات السوق، وأن الدولة يجب أن تدير أعمالها من خلال شبكات يشترك فيها كافة لأنة الأطراف في ظل نوازن للقوى واستقلالية هذه الثبكات، وتوصلت الدراسة أن مشاركة مؤسسات المجتمع المدني تساهم في تقديم الخدمات العامة بشكل يتميز بالرشد الإداري والحد من من

وأهتمت دراسة (علام، 9 × . ب) بوضع تعريف للحكم الموسع بأنه تعاون هادف بين عدة

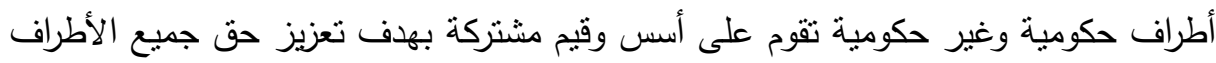

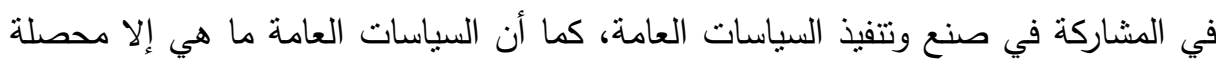

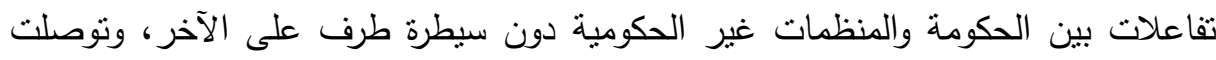
الدراسة أن المنظمات غير الحكومية تعكس الاحتياجات الأساسية للمجتمع وبالتالي فأن اعتبارها شريك سوف يؤدي إلى تحقيق الرضاء العام ورفاهة المجتمع.

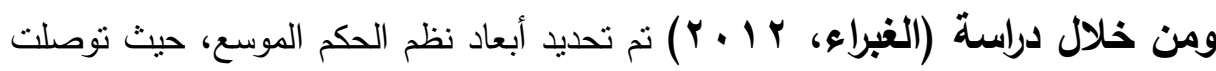
الدراسة إلي ستة أبعاد هي المساءلة، والتمكين، والثفافية، والعدالة، والاستدامة، والتوجه نحو

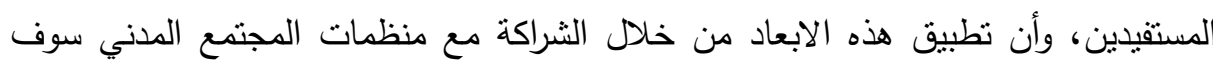
يساهم في الارتقاء بما يتم تقديمة من خدمات للجمهور • وأوضحت دراسة (عزيز، ب ب ب من خلال دراسة تطبيقية لحوكمة قطاع التوعية الصحية أن هناك منظومة للحوكمة تعتمد على المشاركة بين الحكومة والمنظمات غير الحكومية في تأدية النشاط العام تبدأ من عملية المبادأة بصنع السياسة العامة وتتتهي بتقييم

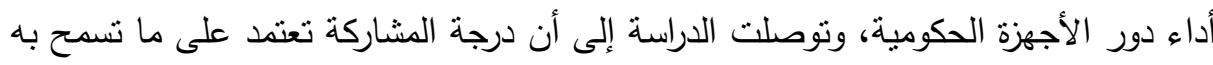

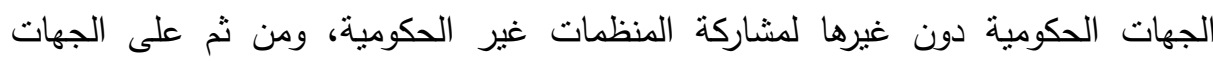
الحكومية ترك مساحة أكبر للمشاركة مع المنظمات غير الحكومية لتأدية النشاط العام. 
وركزت دراسة (أفندي، \& 1 • r ) على ضرورة الاستفادة من المزايا النسبية للمنظمات غير الحكومية في تتفيذ برامج الحكومة التتموية. وتوصلت الدراسة أن أهم المزايا النسبية للمنظمات

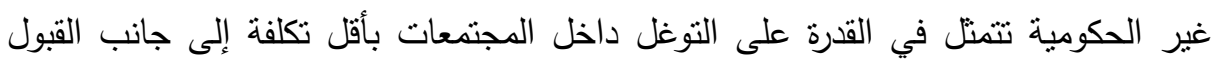

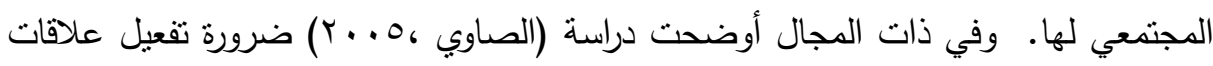
المشاركة الإيجابية بين الحكومة والمنظمات غير الحكومية لتحسين درجة الإفصاح والثفافية وركزت الدراسة على مجال التتمية المحلية كمجال تطبيقي للمشاركة.

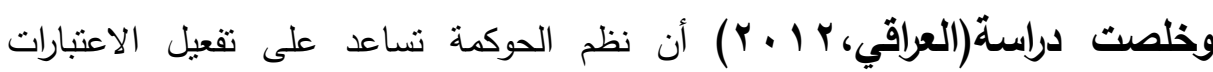
الأخلاقية في أنشطة الإدارة العامة ومؤسساتها والحد من الفساد وعدم العدالة من خلال استخدام مزايا المنظمات غير الحكومية.

\section{الإطالر اللنظليهى}

تم تتاول الاراسة من خلال أريعة محاور على النحو التالي:

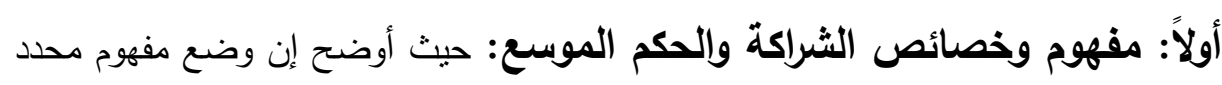
للحكم الموسع أو الشراكة بين الدولة والمجتمع المدني يكاد يكون في غاية الصعوبة فهناك من الصنا

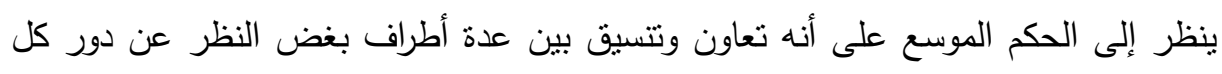

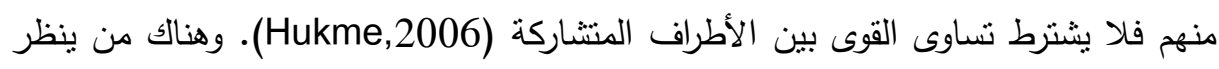

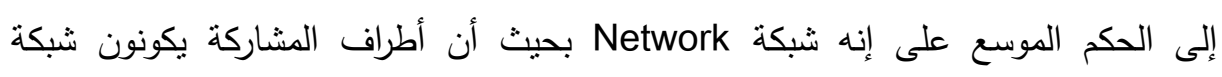
متكاملة ولا نوجد سيطرة من طرف على الآخر (Dean,1999). في حين ينظر آخرون إلى لى لئى

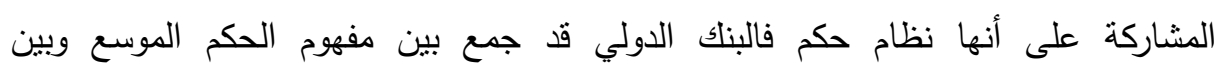
الديمقراطية والاستقرار واحترام حقوق الإنسان والتعددية المؤسسية وعرف المفهوم على انه لهن أسلوب ممارسة القوة في إدارة الموارد الاقتصادية والاجتماعية للبلاد من أجل التتمية.

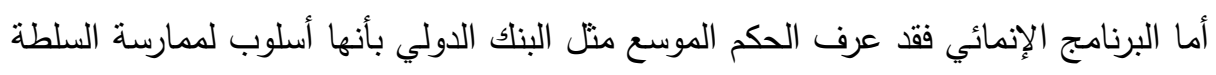

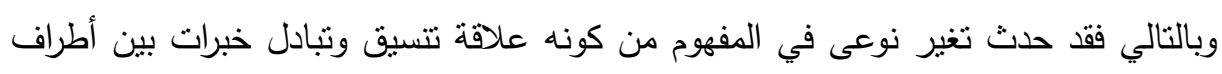


متعددة Partnership إلى أسلوب للحكم الجيد Governance حيث أن مفهوم الحكم

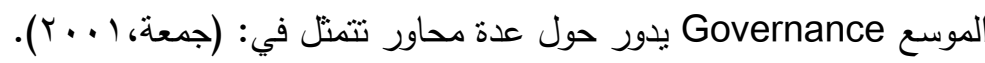
ا-دولة الحد الأدنى: وتعنى عدم تدخل الدولة في تقديم الخدمات العامة وتركها لآليات السوق.

r-إدارة الأعمال الحكومية: بحيث نقدم الدولة خدماتها من خلال أساليب إدارة الأعمال وإدخال قيم جديدة منل المنافسة، وقياس الأداء ورضاء العملاء ... وغيرها من المفاهيم. r-الدولة الايمقراطية: حيث يتم الربط بين الدور الجديد للدولة وما تقدمة من نظم ديمقراطية.

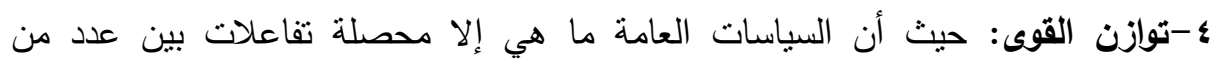

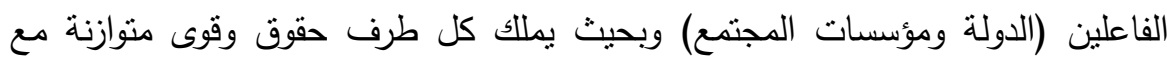
الطرف الأخر . مالمان. ه-الدولة ذات العلاقات الثبكية: ويرى هذا المحور أن الدولة يجب أن تدير أعمالها من خلال شبكات يشترك فيها كافة الأطراف في ظل نوازن للقوى واستقلالية هذه الثبكات.

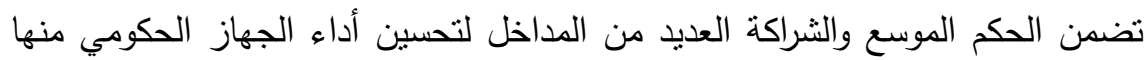
الشراكة بين الحكومة والمنظمات غير الحكومية في إدارة النشاط العام بداية من عملية المبادأة

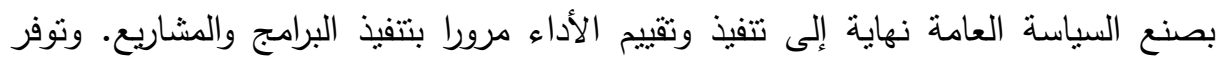

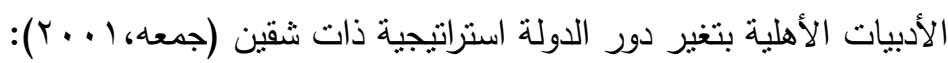
الأول: تركيز أنشطة الدولة على المجالات التي تتلاءم مع قدراتها اذ أن كثير من الدول

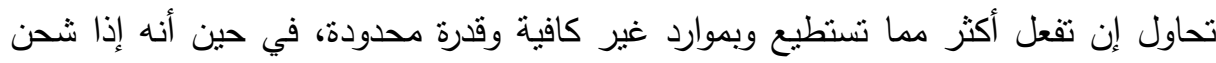
تركيز جها الحكومة على الأنشطة العامة التي لا غنى عنها للتنمية فان ذلك يزيد من إنى فعاليتها. الثاني: البحث في ذات الوقت عن وسائل لتحسين قدرة الدولة عن طريق تتشيط المؤسسات العامة، وتوجيه اهتمام خاص للأبحاث التي تبعث في الموظفين العموميين الحافز على أداء عملهم بصورة أفضل وبمزيد من المرونة. 
ولقد ساند من دعم هذه التوجهات الرغبة في الحصول على الخدمات التي تقدمها المؤسسات الحكومية بجودة أكبر مع عدم تحميل الدولة بنفقات جديدة مقابل هذه الجودة.

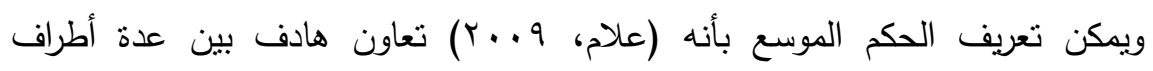
حكومية وغير حكومية تقوم على أسس وقيم مشتركة بهدف تعزيز حق جميع الأطراف في بانه

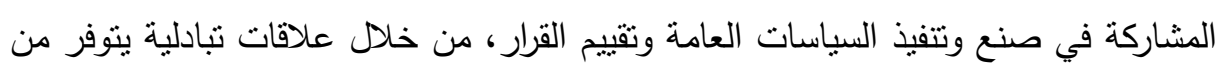

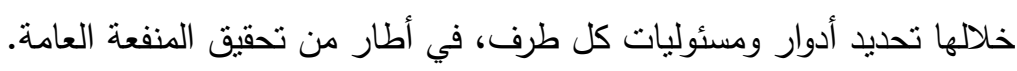

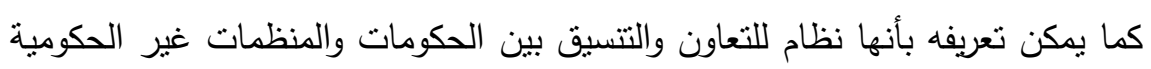

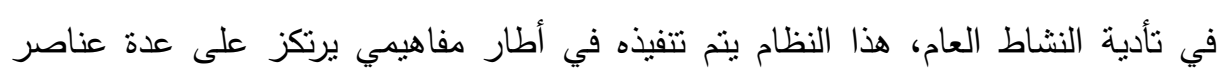

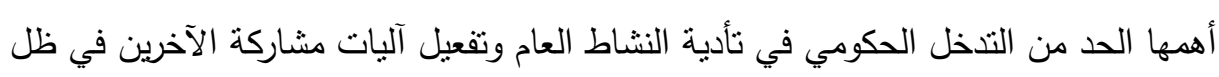
آليات السوق، كما أن السياسات العامة ما هي إلا محصلة تفاعلات بين الحكومة والمنظمات العية

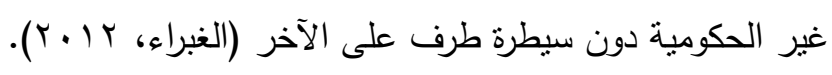

ويرتبط بمفهوم وسمات الحكم الموسع مجموعة من المفاهيم الإدارية الحديثة ومنها: ا. المساعلة: وتعنى حق المواطن في محاسبة مقدم الخدمة بحيث تكون الحكومة مسئولة

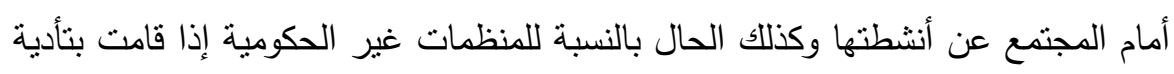

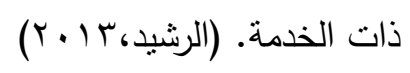

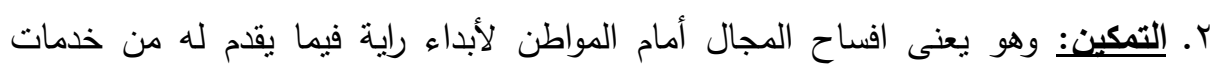

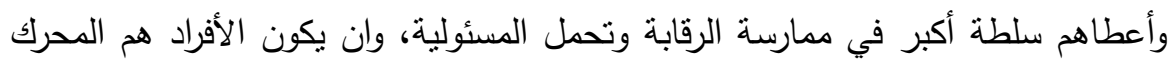

للأداء الحكومي لتوجيهه نحو خدمة مصالحهم.(Saves, 2011)

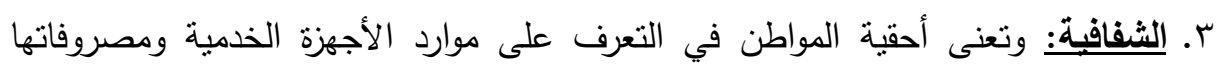

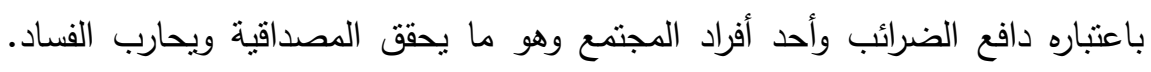

(Gerry, 2014)

ع. العدالة: وتعنى المساواة في الحقوق والواجبات لكافة أفراد المجتمع وضمان الحقوق وتوازن

القوى. 
ه. الاستدامة: وهي تعنى أن أي عملية مشاركة لابد أن تعمل باطراد وانتظام ومن جانب آخر

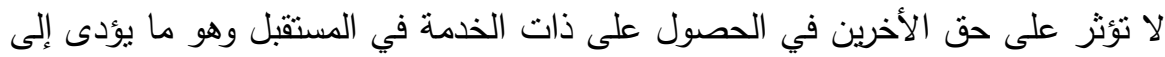

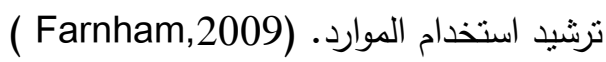

7. التوجه نحو المستفيدين: بحيث يكون المواطن هو محور عمل الحكومة ورضاءه هو الغاية الكبرى للاولة وعليه فإنها تقدم خدماتها بالنوعية والحجم الذي يراها المواطن.

(Nicolas, 2012) V. المنافسة: وتعنى نساوى الفرص أمام كافة الأطراف من حيث المزايا والعيوب وعدم تمييز

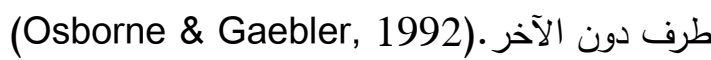
^. القبول الاجتماعي والمشاركة الإبجابية: بحيث تتم عمليات إدارة الخدمات العامة في إطار من القبول الاجتماعي بما يساعد على اثتراك المجتمع في تأدية الخدمة ويحافظ عليها ويرشد مواردها.

كافة هذه المفاهيم يمكن أن توصف بأنها مقومات الحكم الموسع والتي يجب أن نوفرها الحكومات من اجل نجاح عمليات المشاركة مع المجتمع المدني ومنظماته في تقديم الخدمات العامة البيئية. ثانياً: الأثنكال المختلفة للحكم الموسع مع المنظمات غير الحكومية: حظي موضوع الحكم الموسع بين القطاعين الحكومي والأهلي باهتمام كبير من قبل الحكومات في الدول المتقدمة والنامية على حد سواء، بعد أن اتضح بأن عملية التتمية الاقتصادية

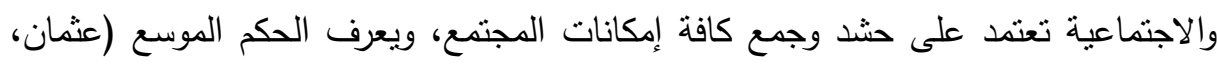

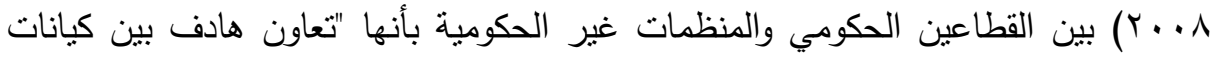

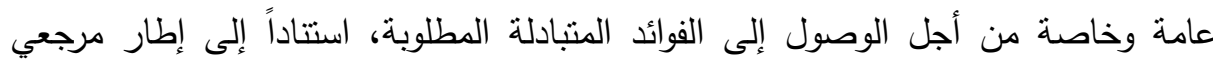
مشترك، وبأنها مفهوم تتموي بعيد المدى يحتاج تحقيق التعاون فيه تجاوز المصالح المتداخلة والمتضاربة - أحياناً - بين الأطراف المعنية. 
وإذا استقرت الدولة على فكرة أنه من مصلحتها ومصلحة المواطن الدخول في شراكة مع المنظمات غير الحكومية فيتم تقسيم الأدوار والأعباء المالية والمخاطرة وما يرتبه بالتبعية من من فئن

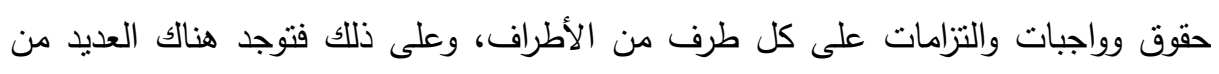

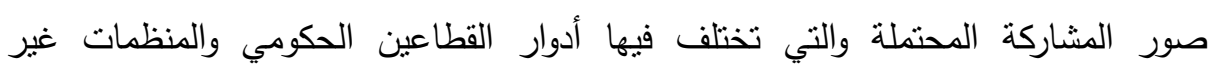

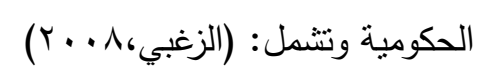
• المشاركة في رسم السياسات البيئية. • المشاركة في تحديد الأولويات وتحديد الاجندة البيئية. الاسناد الكامل لتتفيذ بعض المشروعات البيئية.

ه الاسناد الجزئي لتتفيذ بعض المشروعات البيئية • ت توفير برامج تدريبية وتوعوية.

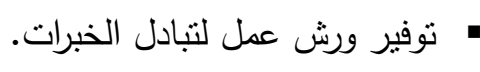
• اتاحة الفرصة للمشاركة في الفعاليات المحلية والدولية.

$$
\text { " الدم الدم التلي. }
$$

وبطبيعة الحال فأن كل أسلوب له مزايا وعيوب، ومنها ما يناسب نشاط دون غيرة، ومن

ثم يبحث متخذ القرار دائما على المناسب فيما بينها. ثالثاً: الحكم الموسع بين الحكومة والمنظمات غير الحكومية. مالها وما عليها: حيث تتعدد وتتباين وجهات النظر بشأن موضوعات وصور الحكم الموسع بين القطاعين

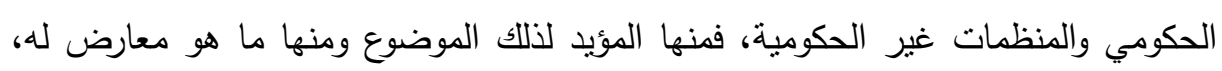

$$
\text { ولكل فريق منهما مبرراته: }
$$

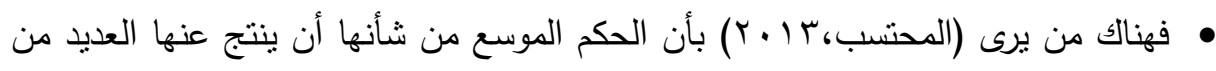

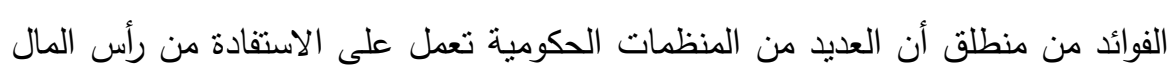

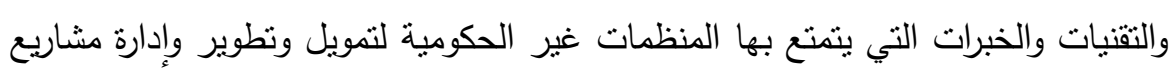
القطاع العام للبنية التحتية لشبكات المياه والنقل والطاقة والاتصالات السلكية واللاسلكية مما يمكن أن يتحول إلى محفز لتنشيط النمو الاقتصادي. لإنية 
وعلى صعيد آخر يظهر فريق آخر من الكتاب والباحثين معوقات وعيوب الحكم الموسع

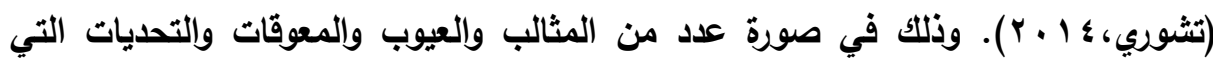
تواجه تلك الحكم الموسع وذلك على النحو التالي:

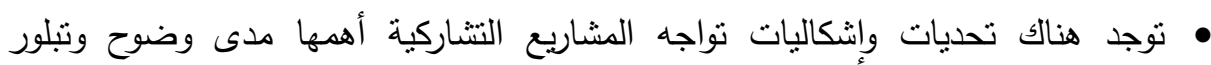
الاستراتيجيات والسياسات والخطط والبرامج حول الحكم الموسع، ومستوى استعداد كلا القطاعين لتحمل أعباء هذه الحكم الموسع على مختلف المستويات، كما أن قرار التشاركية ولئية يحتاج لتوافق سياسي وشعبي. • إضافة إلى مدى استعداد وقناعة وتعاون وتجاوب الأجززة الحكومية والمستويات المتوسطة والدنيا، وهناك خشية من دخول سلوكيات الفساد إلى عملية النشاركية التي ترافق عادة آليات التعاطي مع المنظمات غير الحكومية.

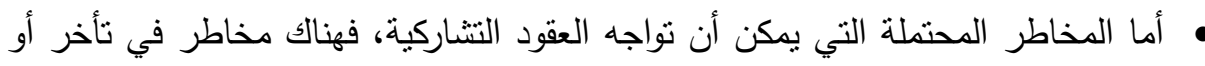
تعثر منح التراخيص والعجز في التمويل وسوء الإدارة أو تدني مسنوى الجودة في الخدمة تواده إلى جانب مخاطر توقف المشروع، والمخاطر الناجمة عن مشكلة تقدير القيمة المستقبلية للمشروع، وغيرها. • صعوبات الاستثمار الأهلي في الخدمات العامة. • إلى جانب غياب الرؤية الاستراتيجية الواضحة والموحدة عند معالجة موضوعات الاتهات التشاركية. • ومن المحاذير أن ينم التوسع في منح الإعفاءات الضريبية والحوافز الإعانات والقروض الرخيصة والأراضي المجانية، وتحميل الجهات الحكومية جزءاً كبيراً من المخاطر .

رابعاً: دور الشراكة بين الدولة والمنظمات غير الحكومية في تحسين الوضع البيئي في مصر: ولعل سعي المنظمات غير الحكومية في حماية البيئة من التلوث ونشر الوعي البيئي من أهم الجهود التي تنذلها هذه المنظمات في هذا الثأن، فمنذ مؤنمر استوكهولم عام 9 ام ، قامت المنظمات غير الحكومية بدور لا غنى عنه في تحديد المخاطر وتقييم

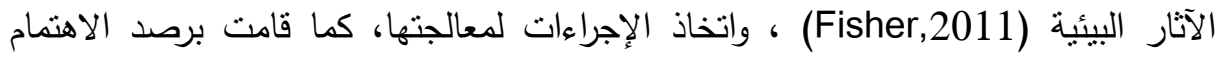


العام والسياسي بالقضايا البيئية والإنمائية، وأصدرت منظمات غير حكومية دولية عديدة . بما فيها المعهد العالمي للمراقبة، والمعهد العالمي للموارد، والاتحاد الدولي لحفظ الطبيعة والموارد ولئه الطبيعية ـ تقارير هامة عن البيئة العالمية، وبعض الجوانب المتعلقة بالبيئة والتتمية، مثل:

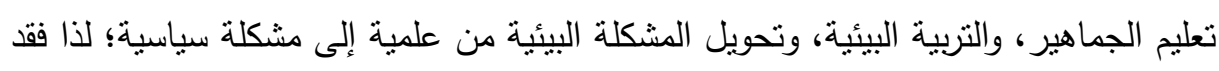

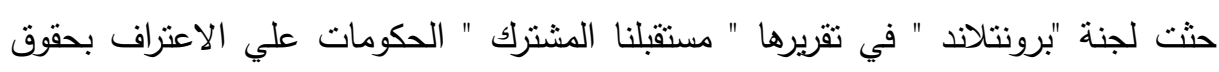
المنظمات غير الحكومية، وتوسيع نطاق الحقوق المتعلقة بها، ومن أهمها: (Durley,2013) 1-حقها في المعرفة وإمكانية الحصول على المعلومات بشأن البيئة والموارد الطبيعية.

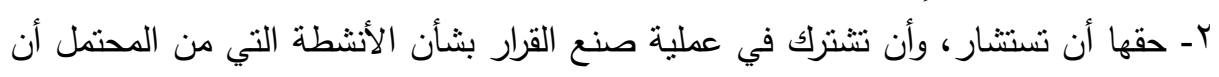

$$
\text { تترك أثناراً كبيرة على بيئتها. }
$$

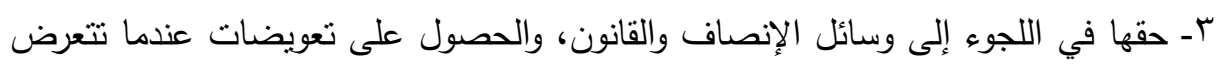

$$
\text { بيئتها إلى تأثنرات خطيرة. }
$$

ولقد ساهمت المنظمات غير الحكومية مساهمات عديدة، وقدمت اقتراحات منتوعة إلى لى

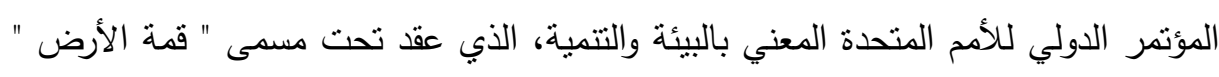

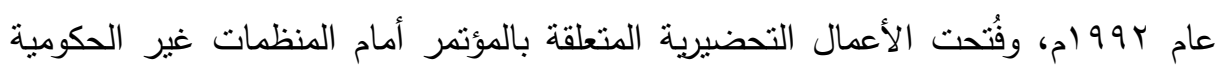
بدرجة غير مسبوقة، وقررت إعطاء أية منظمة غير حكومية لديها علاقة في مجال البيئة

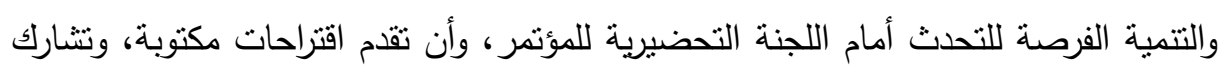
في مناقثات اللجان العامة.

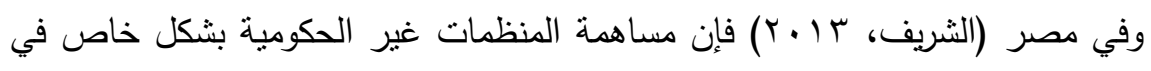
حماية البيئة ونشر الوعي البيئي يحتاج إلى تتسيق الجهود بين المنظمات غير الحئ الحكومية

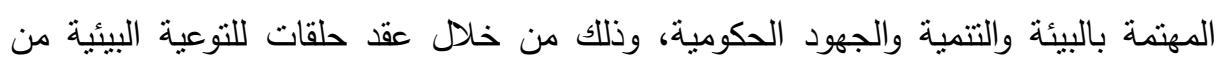

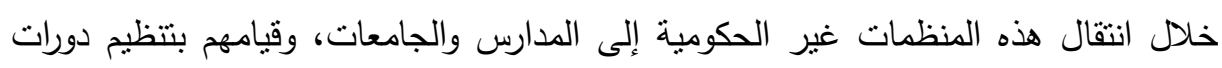

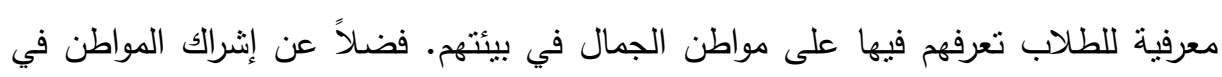
المشروعات البيئية؛ بهذف إكسابه الخبرة والوعي اللازمين لهذه المشكلة.

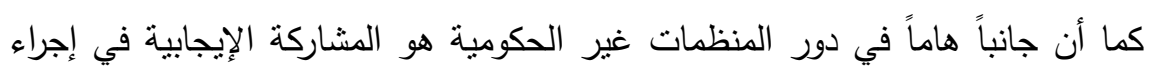

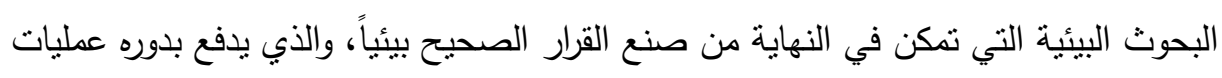

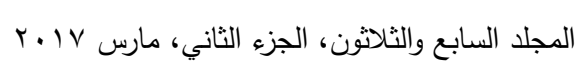


التتمية إلى الأمام دون الإضرار بالموارد الطبيعية التي هي حق أصيل للمجتمع والأجيال

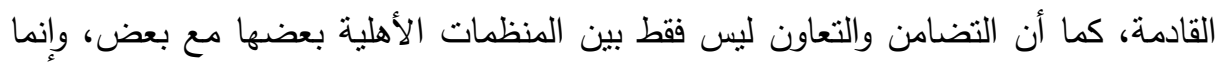

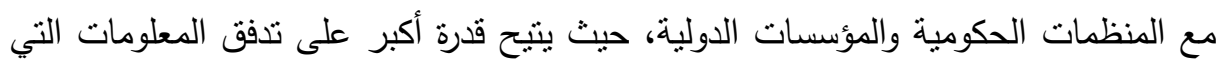

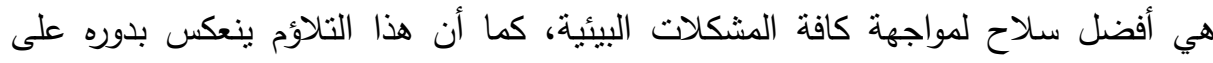

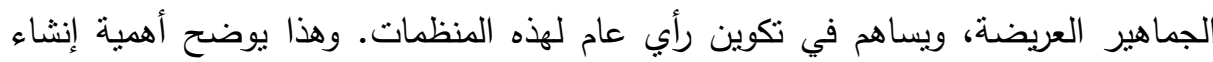

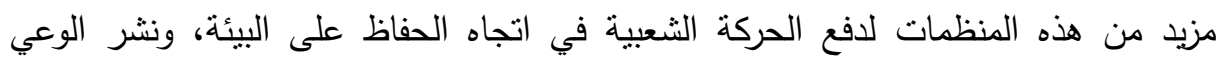
البيئي، والقضاء على العديد من المعوقات التي تُكبل حركة العمل التطوعي في مصر.

\section{منهبية واجبراءاهي القراسلة}

منهج الاراسة: نم استخدام المنهج الوصفي التحليلي: وذلك لدراسة مفهوم ومقومات تطبيق

الحكم الموسع والحوكمة البيئية وأبعادها ومزايا تطبيقها في تحسين الوضع البيئي في مصر .

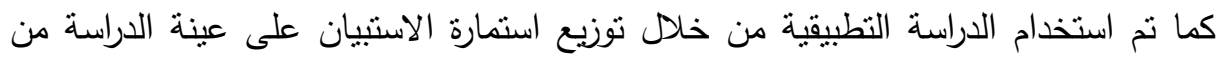
مسئولي المنظمات غير الحكومية العاملة في مجال حماية البيئة بمحافظة القاهرة. أدوات الاراسة: تم تصميم استمارة استبيان تتضمن ثلاثة مجموعات من الأسئلة: المجموعة الأولي: تتتاول إدراك المبحوثين لمفهوم ومزايا الحكم الموسع.

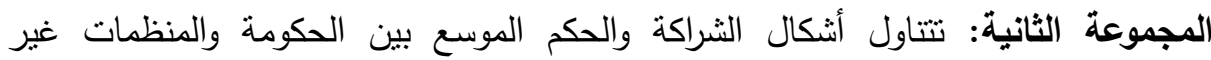
الحكومية في تحسين الوضع البيئي. المجموعة الثالثة: نتتاول آراء عينة الدراسة عن كيفية تطوير آليات المشاركة لتطبيق الحكم الموسع في مجال حماية البيئة. وتم استخدام مقياس ليكرت الخماسي بحيث تعبر الاستجابة موافق بشدة ( م درجات)

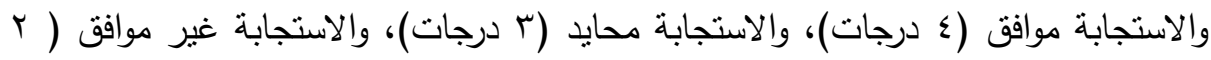

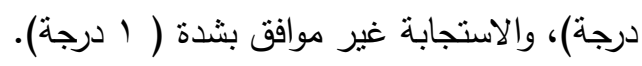


صدق وثبات الاستبانة:

ا-صدق المحكمين " الصدق الظاهري" : عرض الباحث الاستبانة على مجموعة من

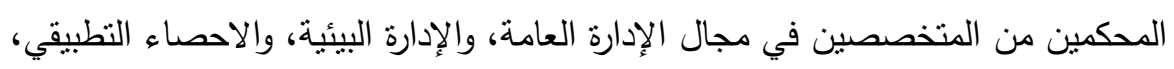

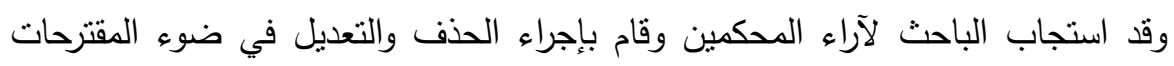
المقدمة وبذلك خرجت الاستبانة في صورتها النهائية.

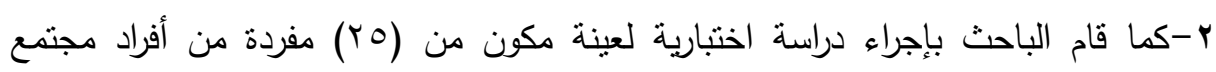
الدراسة للتعرف على درجة وضوح وفهم فقرات الاستبانة من وجهة نظر المبحوثين وقد نم إعادة صياغة بعض الفقرات لتكون أكثر وضحاً وفهماً.

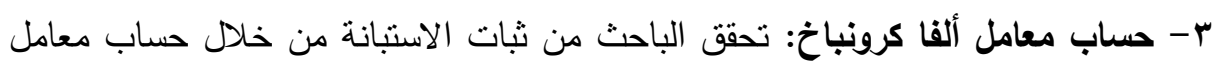

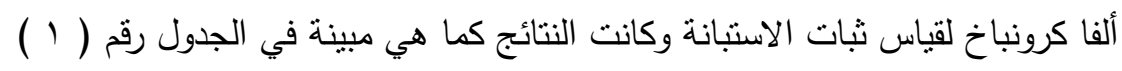
جدول رقم(1): معامل ألفا كرونباخ لقياس ثبات الاستبانة

\begin{tabular}{|c|c|c|c|}
\hline الألصدق" & كرونباخ آلفاخ & عدد الفقرات & 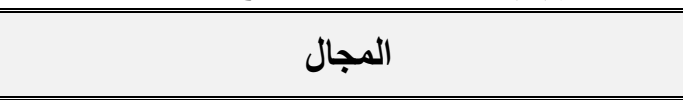 \\
\hline$\cdot, 9 \vee 7$ & $\cdot, 90 r$ & 1. & ابعاد مفاهيم ومزايا الحكم الموسع \\
\hline$\cdot, 9 \times 1$ & $\cdot, 9 \leqslant \pi$ & V & الحكومية اشكال الثراكة بين الحكومة والمنظمات غير \\
\hline$\cdot, 9 \vee 0$ & $\cdot, 901$ & 0 & الوضعاد البيئيت تطبيق الحكم الموسع في تحسين \\
\hline$\cdot, 9 \lambda 1$ & $\cdot, 9 \leqslant \wedge$ & rY & جميع المجالات معاً \\
\hline
\end{tabular}

* الصدق الذاتي = الجذر التربيعي الموجب لمعامل ألفا كرونباخ

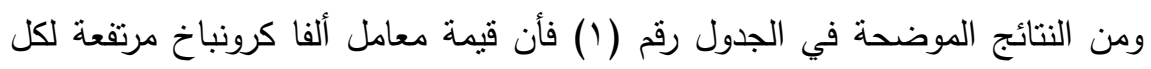

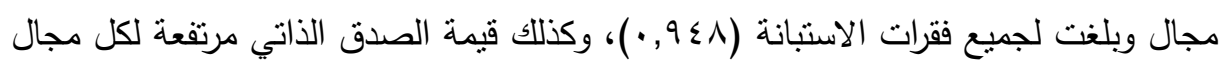
وبلغت لجميع فقرات الاسنبانة ( (1) 9 • ) وهذا يعني أن الثبات مرتفع ودال إحصائياً. الأسلوب الإحصائي المستخدم في تحليل البيانات: اعتمدت الدراسة على استخدام حزمة البرامج الإحصائية SPS (Statistical Package for Social Science) الإصدار ا, Y ، ، حيث نم استخدام الأساليب الاحصائية الوصفية منل التوزيع التكراري ، والنسب المئوية، والوسط الحسابي، والانحراف المعياري. 
أنواع البيانات ومصادر الحصول عليها: نم الجمع بين مصادر البيانات الثانوية والأولية على النحو النالي: - ماتئ البيانات الثانوية: اتجه الباحث لتغطية الإطار النظري للبحث الى مصادر البيانات الثانوية والتي تمثلت في الكتب والمراجع العربية والأجنبية ذات العلاقة، والدوريات والدراسات السابقة والبحوث والتقارير التي تتاولت موضوع الدراسة. البيانات الأولية: وتمنلت هذه البيانات في التعرف على آلىاء على عينة الدراسة حول إدراك ابعاد

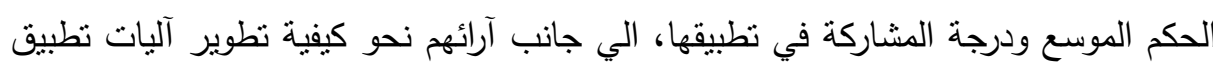

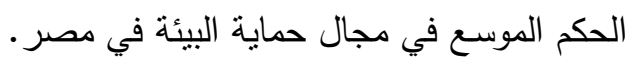
مجتمع وعينة الاراسة: ويتمثل مجتمع البحث في العاملين على إدارة المنظمات غير الحكومية العاملة في مجال حماية البيئة في محافظة القاهرة وعددهم 19 منظمة بإجمالي

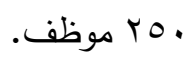

ولكون مجتمع البحث منمانل فقد تم اختيار عينة عشوائية، ولتحديد حجم العينة تمت هوثت الاستعانة بالجداول الاحصائية والتي تراعي تمثيل العينة للمجتمع ودرجة الدقة المطلوبة وذلك

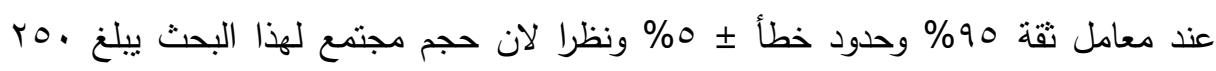

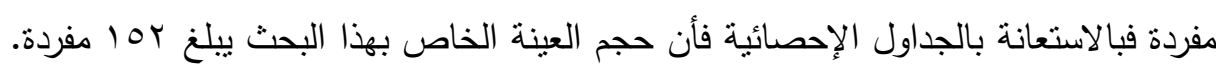

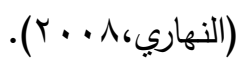
حدود البحث: تم نطبيق البحث على المنظمات غير الحكومية العاملة في مجال حماية

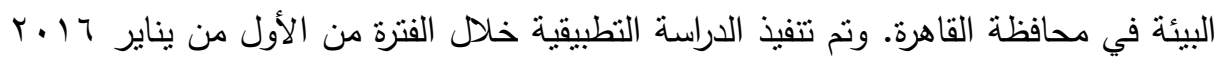
حتى نهاية مارس 17 ( • بم.

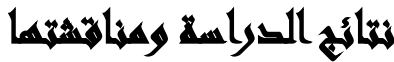

للإجابة على أسئلة الدراسة فقد تم حساب بعض المقاييس الإحصائية الوصفية مثل

$$
\text { التكرارات والنسب والوسط الحسابي والانحراف المعياري. }
$$


كما تم استخدام اختبار (T) لمعرفة ما إذا كان منتسط درجة الاستجابة قد وصلت الي

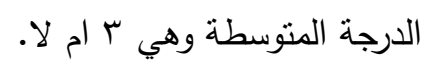
السؤال الأول: ما مدى إدراك المنظمات غير الحكومية لدفهوم ومزايا الحكم الموسع في تحسين الوضع البيئي؟

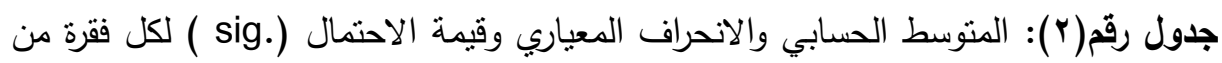

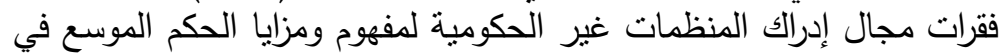

\begin{tabular}{|c|c|c|c|c|c|c|c|}
\hline الَترَبَبِ & 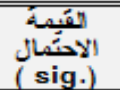 & الاخَّبَّة & 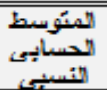 & الالمعيانى & لالحستوبطى & لالفقرَة & ? \\
\hline $\mathrm{v}$ & $=, \ldots$ & $1 \cdot, A T$ & $7 \times, 0 \leq$ & $\cdot, 78$ & $T, r \wedge$ & 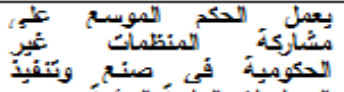 & 1 \\
\hline$r$ & $=, \ldots$ & $1 \mathrm{r}, \mathrm{V}$ & $v_{*}, r q$ & •,AT & $r$, or & 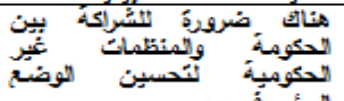 & $r$ \\
\hline$T$ & $=+, \ldots$ & $1 \mathrm{~A}, \mathrm{VA}$ & $v \leq, 0$. & $\cdot, \mathrm{v} \leq$ & $r, V T$ & 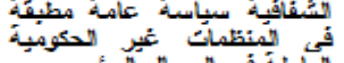 & $r$ \\
\hline$\leq$ & $=, \ldots$ & $1,7$. & 79,01 & $\cdot, \mathrm{VT}$ & $T, \pm \wedge$ & 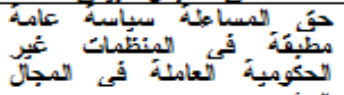 & $\leq$ \\
\hline 0 & $=, \ldots$ & $1 \cdots$ & $7 A, 17$ & $\cdot, \mathrm{VA}$ & $r, \pm 1$ & 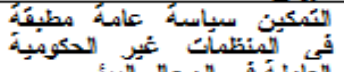 & 0 \\
\hline 7 & $=, \ldots$ & $1+, 14$ & $7 v, 9 \leq$ & $\cdot, \mathrm{vo}$ & $r, \varepsilon$ & 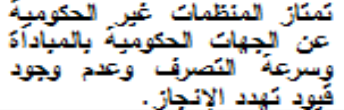 & 7 \\
\hline a & $=, \ldots$ & $v, r$ & $70,+1$ & $\cdot, \mathrm{iv}$ & $r, r_{0}$ & 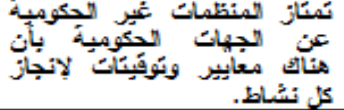 & $\mathrm{v}$ \\
\hline 1 & $=, \ldots$ & $r, \pm 9$ & $v_{0,1}$. & $\cdot, 7 \mathrm{~V}$ & $r, v_{0}$ & 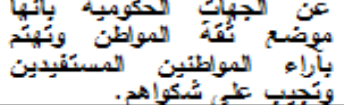 & A \\
\hline$\wedge$ & $=, \ldots$ & T,AT & $\pi, 14$ & $\cdot, A_{4}$ & $r, r$ & 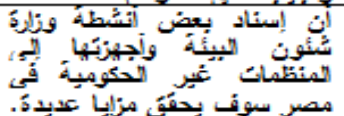 & $a$ \\
\hline 1. & $=, \ldots$ & $r, v a$ & ${ }^{2} \mathrm{r}, \mathrm{VY}$ &., 90 & $r, 19$ & 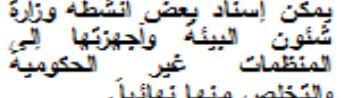 & 1. \\
\hline & $=\ldots \ldots$ & $1 \% .+4$ & $71,7 \leq$ & $.7 \leqslant$ & $r, \pm T$ & 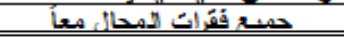 & \\
\hline
\end{tabular}

المتوسط الحسابي دال احصائياً عند مستوى دلالة $0.05=0$.

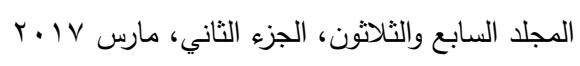


يتضح من الجدول رقم (Y) ان ترتيب درجات إدراك المنظمات غير الحكومية لمفهوم ومزايا الحكم الموسع في تحسين الوضع البيئي جاءت على النحو التالي:

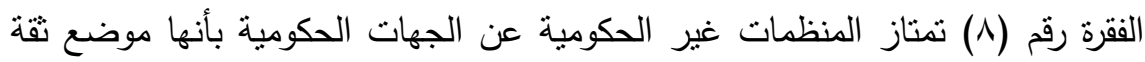
المواطن وتهنم بآراء المواطنين المستقيدين وتجيب على شكواهم جاءت في المرتبة الأولى

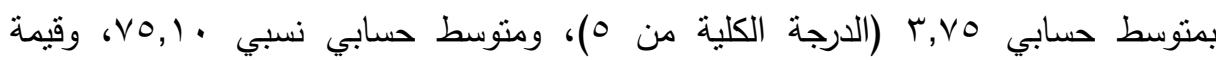

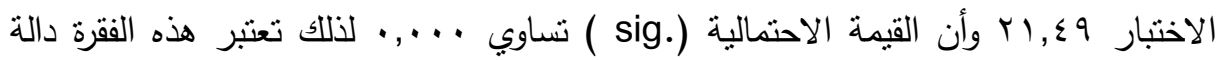

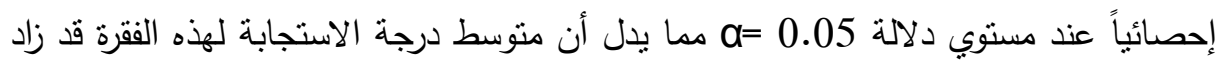
عن الدرجة المتوسطة r وهذا يعني أن هناك موافقة من قبل افراد العينة علي هذه الفقرة وبالتالي حصلت علي اعلي درجة موافقة ويعزو الباحث ذلك الي إدراك العاملين في المنظمات غير الحكومية لنقة المواطنين فيما يتم تقديمة للمجتمع والقدرة على التوغل داخل المجتمع أكثر من الأجهزة الحكومية.

كما يتضح من الجدول رقم (Y) أن الفقرة رقم ( • () يمكن إسناد بعض أنشطة وزارة شئون البيئة وأجهزتها إلى المنظمات غير الحكومية والتخلص منها نهائياً جاءت في المرنبة

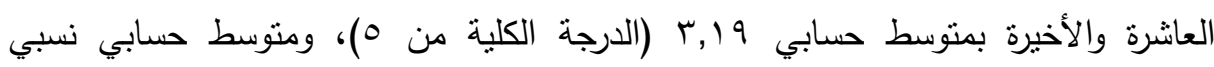

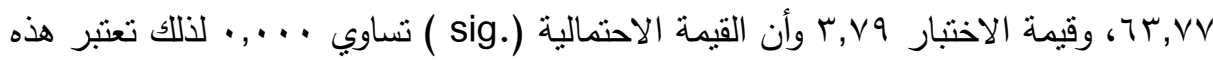

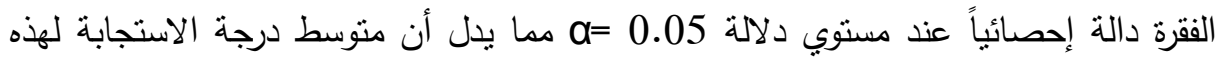

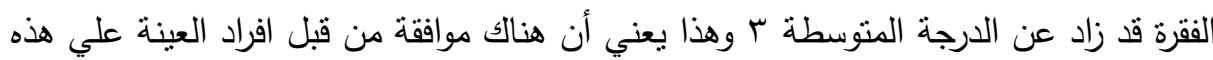
الفقرة وبالتالي حصلت علي أقل درجة موافقة ويعزو الباحث ذللك الي إدراك العاملين في

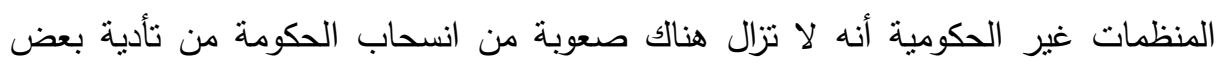
المشروعات البيئية وترك المسئولية للقطاع الأهلي حيث أنه غير مؤهل بالثكل الكافي لتأدية

$$
\text { النشاط بعيدا عن الحكومة. }
$$

وبشكل عام يمكن القول أن المتوسط الحسابي يساوي بــبـ ، والمتوسط الحسابي

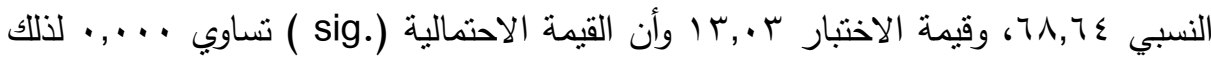
تعتبر هذه الفقرة دالة إحصائياً عند مستوي دلالة O=0.05 مما يدل أن متوسط درجة 
الاستجابة لهذا المجال يختلف جوهريا عن الدرجة المنوسطة r وهذا يعني أن هناك موافقة من قبل افراد العينة علي فقرات هذا المجال، وهو ما يعني إدراك عينة البحث لمفهوم ومزايا الحكم

$$
\text { الموسع في تحسين الوضع البيئي. }
$$

السؤال الثاني: ما هي اشكال الثراكة بين الحكومة والمنظمات غير الحكومية في تحسين الوضع البيئي؟ جدول رقم(؟): المتوسط الحسابي والانحراف المعياري وقيمة الاحتمال (sig ) لكل فقرة من فقرات مجال اثكال الثراكة بين الحكومة والمنظمات غير الحكومية في ولئي

تحسين الوضع البيئي

\begin{tabular}{|c|c|c|c|c|c|c|c|}
\hline التَربتِب & $\begin{array}{l}\text { الاحتَمِمالة } \\
\text { ( sig.) } \\
\end{array}$ & الاخِبَبة & الحستوبى النسبط & 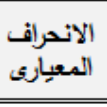 & الحستوسب & الفقرة & a \\
\hline 。 & $*, \ldots$ & $\varepsilon, \leqslant 0$ & $7 \leqslant, 9$. & $1, \cdot 7$ & $r, r_{0}$ & 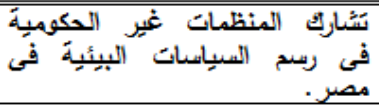 & 1 \\
\hline$\varepsilon$ & $*, \ldots$ & $\bullet, \wedge \wedge$ & 70,94 & $\cdot, 9 \vee$ & r & 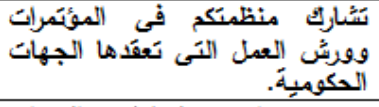 & $r$ \\
\hline 1 & $*, \ldots$ & $15,9 \leq$ & $v \varepsilon,+1$ & •, & $r, v$ & 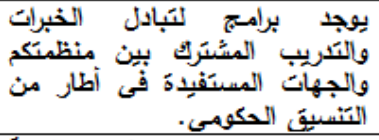 & $r$ \\
\hline $\mathrm{v}$ & $*, ., 4$ & $1, \vee_{7-}$ & ०४,११ & $1, .9$ & $r, q$ & 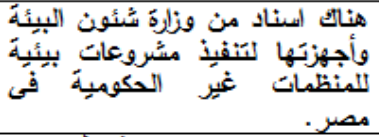 & $\mathfrak{\varepsilon}$ \\
\hline$r$ & $\cdots$ & $\Lambda, r_{0}$ & $\mathrm{in,rv}$ & $\cdot, 9 \vee$ & $r, \varepsilon r$ & 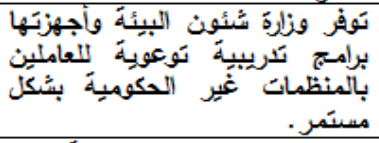 & 0 \\
\hline$r$ & $*, \ldots$ & $9,+7$ & 79,40 & $\cdot, 99$ & $r, \varepsilon V$ & 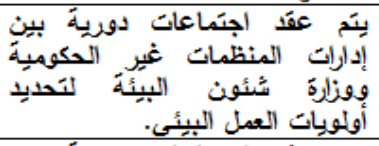 & 7 \\
\hline 7 & $*, \cdot r$. & $r, . T$ & $T Y, 1 \leq$ & $1, .9$ & $r, 1 r$ & 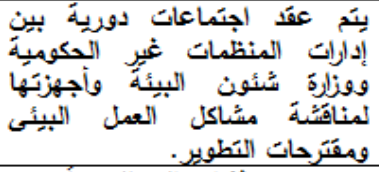 & v \\
\hline & $*, \ldots$ & $7, \wedge \mathrm{Y}$ & $77,1 Y$ &.,$\wedge_{7}$ & 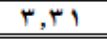 & جمبِع فَرَات المجال معاً & \\
\hline
\end{tabular}

المتوسط الحسابي دال احصائياً عند مستوى دلالة 0.05 
يتضح من الجدول رقم (r) ان ترتيب درجات مجال اثكال الثراكة بين الحكومة والمنظمات غير الحكومية في تحسين الوضع البيئي جاءت على النحو التالي:

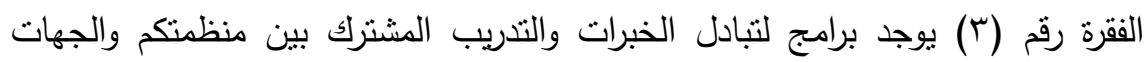

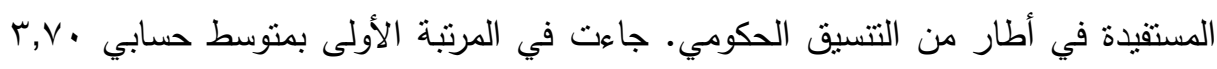

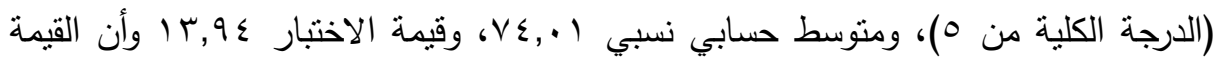

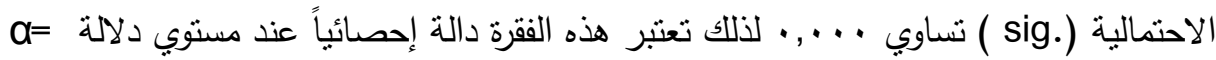

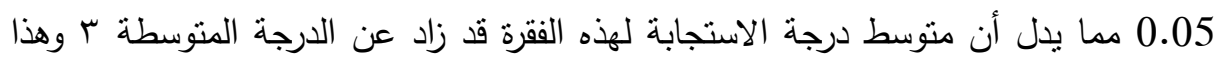

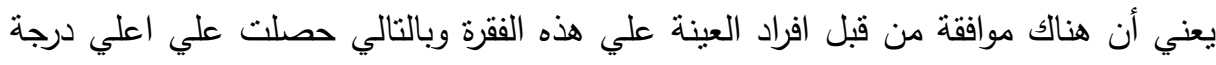
موافقة ويعزو الباحث ذللك الي قيام جهاز شؤون البيئة بعقد دورات تدريبية بصورة دورية ودعوة

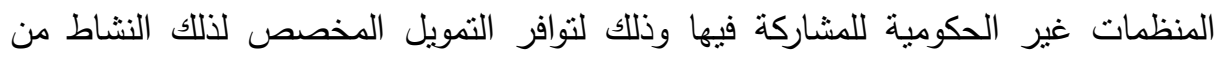
خلال المنح المباشرة من بعض الدول إلي جانب بعض المؤسسات البحثية في المجال البيئي.

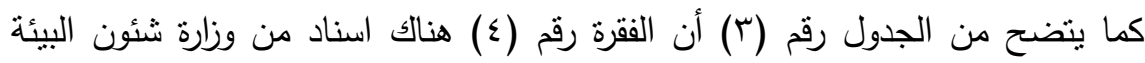

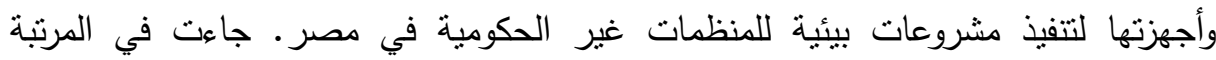

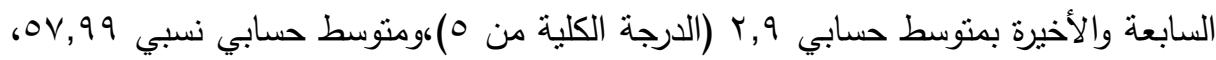

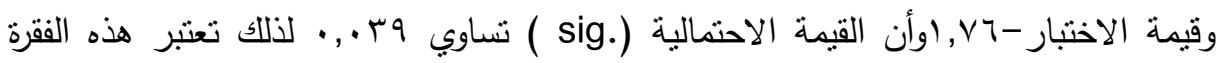

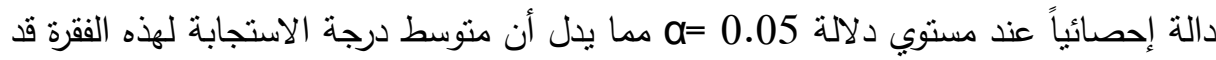
أنخفض عن الدرجة المتوسطة ب وهذا بعني أن هناك عدم موافقة من قبل افراد العينة علي

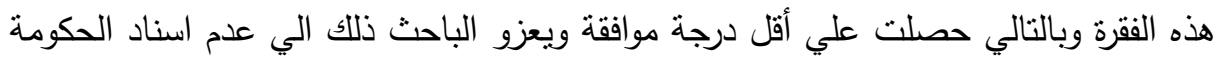
لمشروعات بيئية مستقلة للمنظمات غير الحكومية في مصر وبخاصة لارتباط تللك المشروعات بحجم تمويل ضخم وتعدد العلاقات التظظيمية مع جهات حكومية أخري في فئه التنفيذ. وبشكل عام يمكن القول أن المتوسط الحسابي يساوي اس,r ، والمنوسط الحسابي

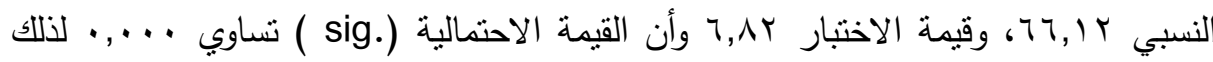
تعتبر هذه الفقرة دالة إحصائياً عند مستوي دلالة O=0.05 مما يدل أن متوسط درجة 
الاستجابة لهذا المجال يختلف جوهريا عن الدرجة المتوسطة ب وهذا يعني أن هناك موافقة من

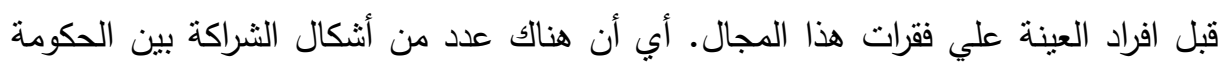
والمنظمات غير الحكومية يتمثل في المشاركة في ورش العمل والفعاليات والدورات التدريبية، ولكنها لازالت تحتاج الي المزيد من الارتقاء واسناد المشروعات للمنظمات غير فير فئه الحكومية للنتفيذ.

السؤال الثالث: ما هي مقومات تطوير تطبيق الحكم الموسع في تحسين الأوضاع البيئية في مصر؟ جدول رقم(ء): المتوسط الحسابي والاتحراف المعياري وقيمة الاحتمال (sig )لكل فقرة من فقرات مجال مقومات تطوير نطبيق الحكم الموسع في تحسين الأوضاع الحراع البيئية في مصر

\begin{tabular}{|c|c|c|c|c|c|c|c|}
\hline التربتِب & 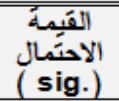 & الاخَبِّة & الحستابى النسبط & المعياري & الحستابى & الفقرة & a \\
\hline$r$ & $*, \ldots$ & $19, \wedge$ & $v 0, q T$ & $\cdot, \mathrm{\vee} \vee$ & $r, \Lambda$. & 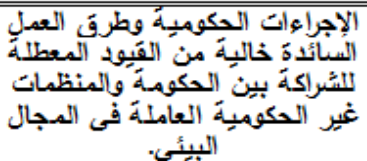 & 1 \\
\hline 1 & $*, \ldots$ & (1,9) & $\mathrm{VA,Y}$ & $\cdot, \wedge$. & ए,q & 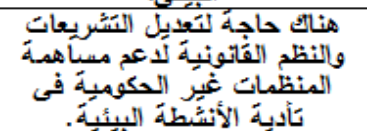 & $r$ \\
\hline$r$ & $*, \ldots$ & $r, i v$ & $\mathrm{v} v, \ldots$ & $\cdot, \mathrm{V}_{0}$ & $r, \wedge 0$ & 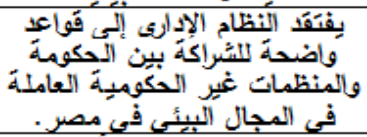 & $r$ \\
\hline$\varepsilon$ & $*,+, q$ & $1 \leq, 7 V$ & $\mathrm{Vr}, \mathrm{r}$. & $\cdot, \wedge \vee$ & ז, & 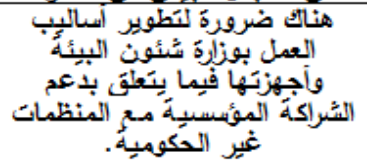 & $\varepsilon$ \\
\hline 0 & $*, \ldots$ & $11,0 \mathrm{~V}$ & $v \cdot, 90$ & $\cdot, 91$ & $r, 00$ & 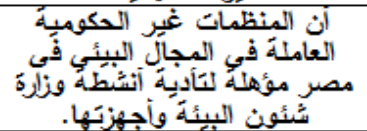 & 0 \\
\hline & $*, \ldots$ & $r 1, \varepsilon 9$ & $\mathrm{vo,1}$. & $\cdot, \wedge_{7}$ & $r, v_{0}$ & جمبع فقرَاتَ المجال معاً & \\
\hline
\end{tabular}

المتوسط الحسابي دال احصائياً عند مستوى دلالة 0.05 
يتضح من الجدول رقم (ع) ان ترنيب درجات فقرات مجال مقومات نطوير تطبيق الحكم

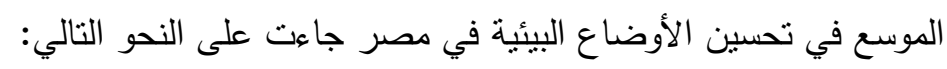

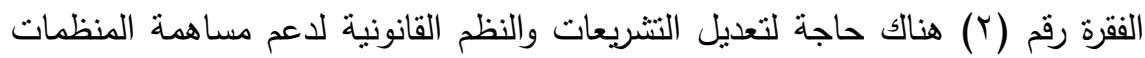

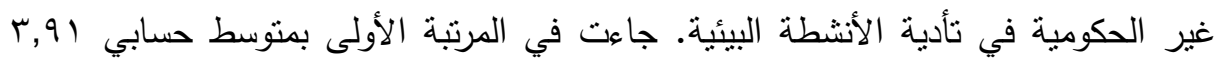

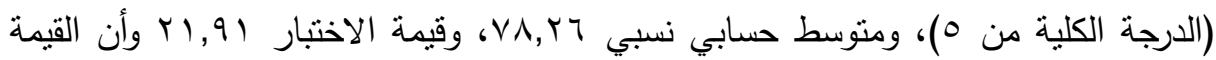

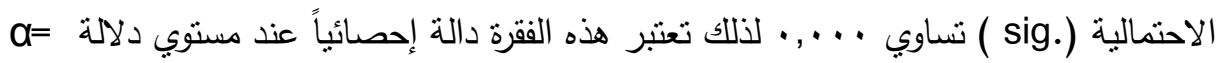

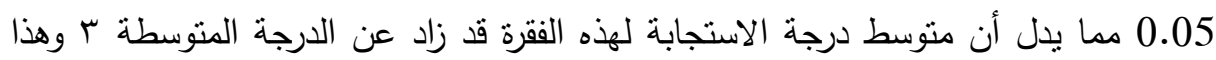

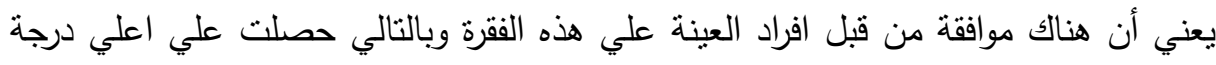

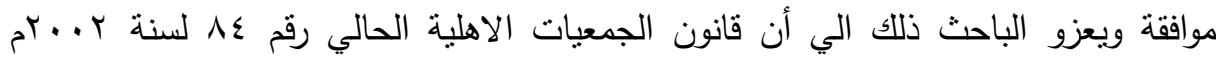

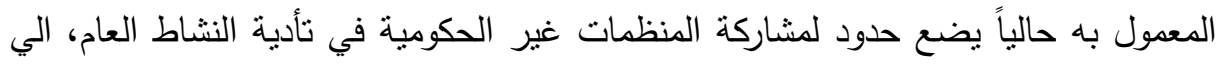

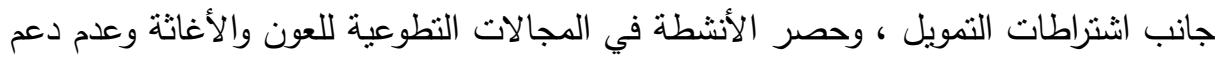
الأنشطة التتموية.

كما يتضح من الجدول رقم (§) أن الفقرة رقم (0) أن المنظمات غير الحكومية العاملة في المجال البيئي في مصر مؤهلة لتأدية أنشطة وزارة شئون البيئة وأجهزتها. جاءت في

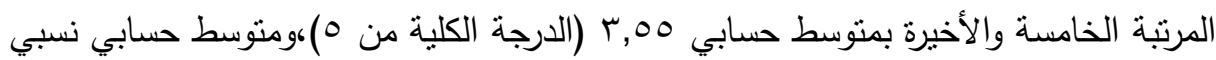

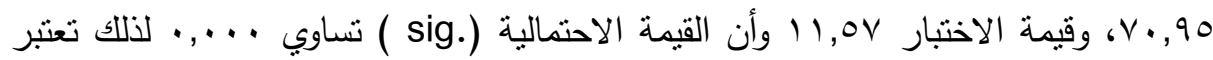

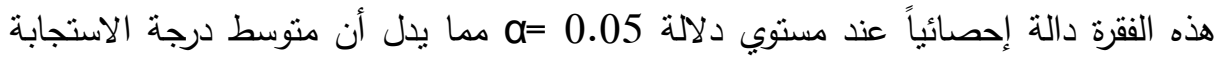

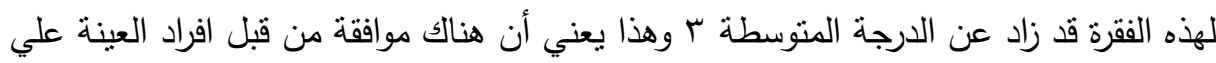

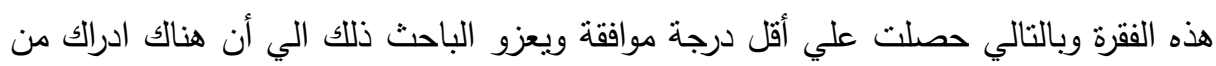

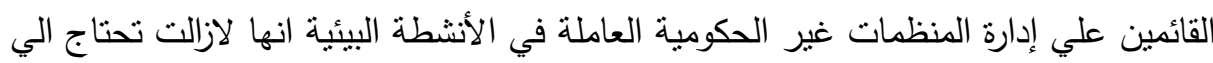
مزيد من التأهيل والإعداد وبناء القدرات حتي تستطيع المشاركة بشكل أكثر فعالية في تأدية 


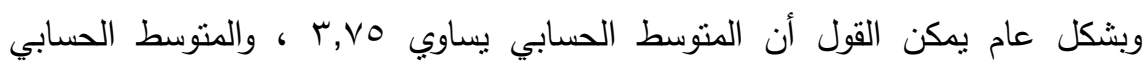

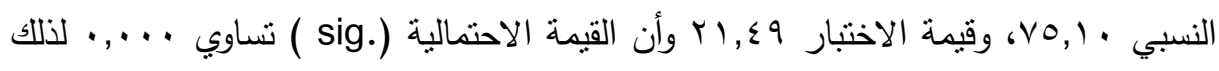

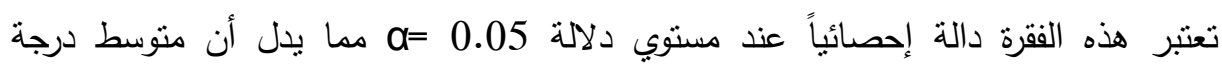

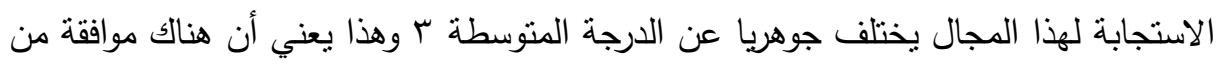

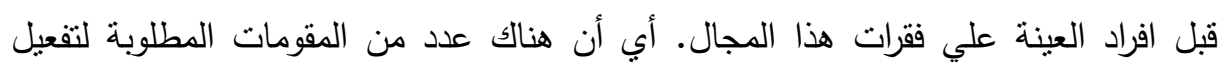

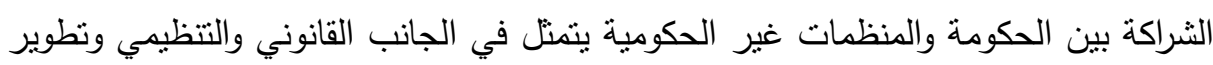
النتريعات وبناء قدرات المنظمات غير الحكومية.

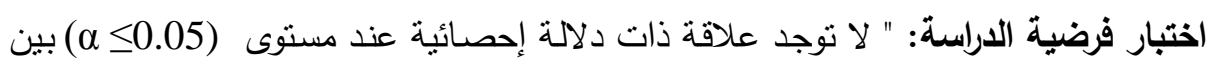

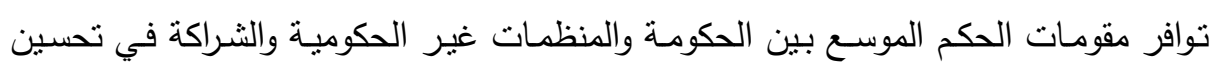

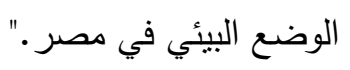

جدول رقم(ه): معامل الارتباط بين أبعاد الحكم الموسع والثراكة في تحسين الوضع البيئي

\begin{tabular}{|c|c|c|c|}
\hline & & \multicolumn{2}{|l|}{ في مصر } \\
\hline $\begin{array}{c}\text { (القيمة الاحتمال } \\
\text { ( sig.) }\end{array}$ & معامل بيرسون & البند & b \\
\hline * *, , & $\cdot, 7 V V$ & الإجراءات الحكومية وطرق العمل السائدة. & 1 \\
\hline$*, \ldots$ & $\cdot, 7$ Tro $^{\circ}$ & النتشريعات والنظم القانونية. & r \\
\hline$*^{*}, \ldots$ & $\cdot, 79$. & النظام الإداري. & $\mu$ \\
\hline$* \cdot, \cdot r q$ & $\cdot, V Y Y$ & تطوير أساليب العمل. & $\varepsilon$ \\
\hline$*^{*} \cdot, \ldots$ & $\cdot, \mathrm{V} \cdot \mathrm{O}$ & تأهيل المنظمات غير الحكومية. & 0 \\
\hline$*, \ldots$ & $\cdot, \wedge \cdot \Lambda$ & آبعاد الحكم الموسع & \\
\hline
\end{tabular}

$$
\text { المتوسط الحسابي دال احصائياً عند مستوى دلالة } 0.05
$$

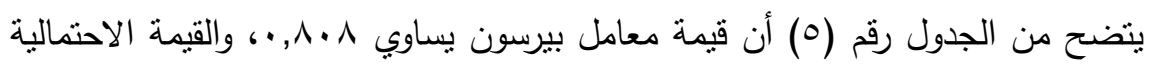

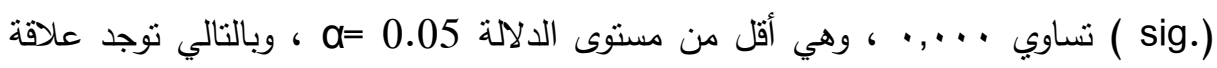

$$
\text { طردية موجبة. }
$$

ويتضح ثثوت عدم صحة فرضية العدم وبالتالي قبول الفرضية البديلة وهي توجد علاقة

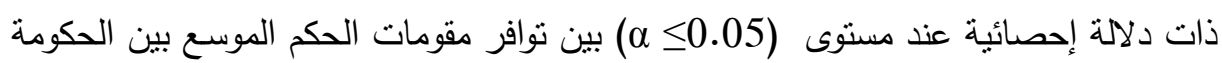
والمنظمات غير الحكومية والثراكة في تحسين الوضع البيئي في مصر . 


\section{اللزوكيامت}

بناء على النتائج التي أسفرت عنها الدراسة والملاحظات التي قدمتها عينة الاراسة أمكن الخروج بمجموعة من التوصيات على النحو التالي:

ا. ضرورة تطوير الإطار التشريعي المدعم للعلاقة بين الحكومة والمنظمات غير الحكومية متضمنة مجموعة القوانين والتتريعات الصادرة ولوائحها التتفيذية، ومجموعة الإجراءات

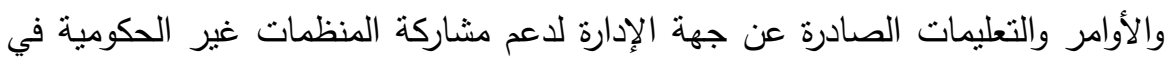
تتفيذ الأنشطة العامة البيئية. r. أتاحه الفرصة لمشاركة المنظمات غير الحكومية في وضع أولويات العمل البيئي

$$
\text { والمساهمة في رسم السياسات البيئية. }
$$

r. الاستفادة من المزايا النسبية للمنظمات غير الحكومية والمنمثلة في ثقة المجتمع، والقدرة على التوغل داخله لتنفيذ الأنشطة البيئية. ع. التتسيق بين جهاز شئون البيئة والمنظمات غير الحكومية في تتفيذ الأنشطة التوعوية لكي لا تحدث ازدواجية في التنفيذ وإهدار للمال والوقت. ه. العمل على التنسيق بين المنظمات غير الحكومية العاملة في ذات المكان أو النشاط وأنشاء تشبيكات بينهم لكي يحدث تكامل فيما بينهم.

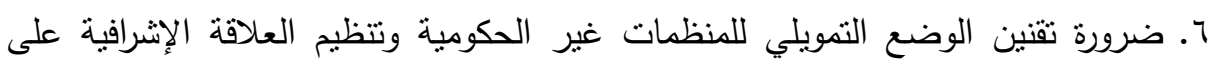
التمويل الأجنبي للمنظمات غير الحكومية.

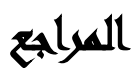

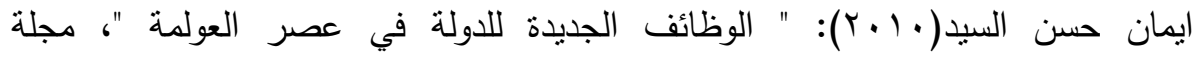
الديمقراطية، العدد الثالث، القاهرة: مركز الدراسات السياسة والاستراتيجية

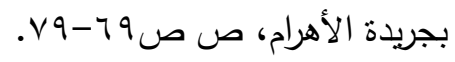

بثينة المحتسب(r ا • ץ): "الحكم الموسع بين القطاعين العام والخاص كأداة لتحقيق التتمية المستدامة"، مؤتمر الحكم الموسع بين القطاعين العام والخاص، القاهرة:

$$
\text { المنظمة العربية للتنمية الإدارية. }
$$




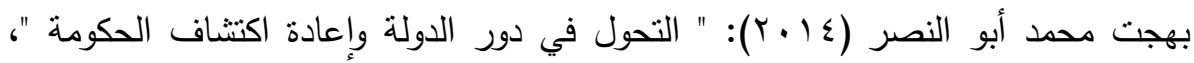

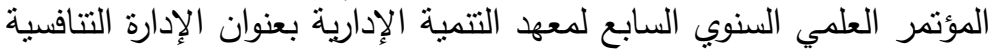

للمشروعات في ظل التحولات العالمية الجديدة، أبو ظبي: وجـ- ـ ديسمبر.

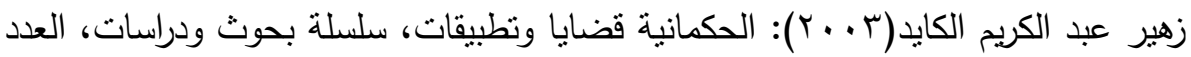

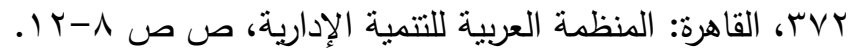

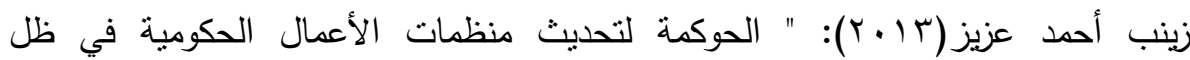

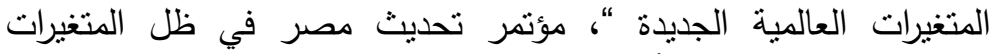
العالمية الجديدة، القاهرة: أكاديمية السادات للعلوم الإدارية، مركز البحوث. سعد طه علام(9 . . ب)، التتمية والدولة، القاهرة: دار طيبة للنشر والتوزيع.

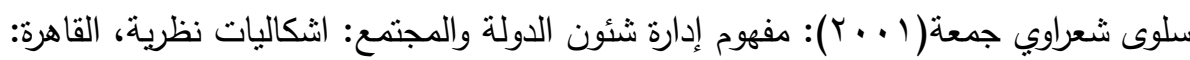
مركز دراسات الإدارة العامة كلية الاقتصاد والعلوم السياسية - جامعة الفئة

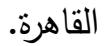

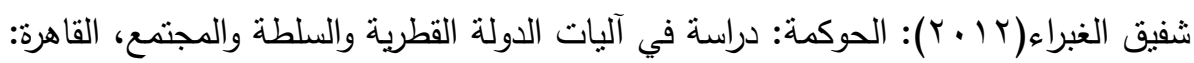
مركز بن خلدون للاراسات الإنمائية.

عادل محمود الرشيد(ب ( • ب): إدارة الحكم الموسع بين القطاعين العام والخاص (المفاهيم النماذج - النطبيقات)، القاهرة: المنظمة العربية للتنمية الإدارية.

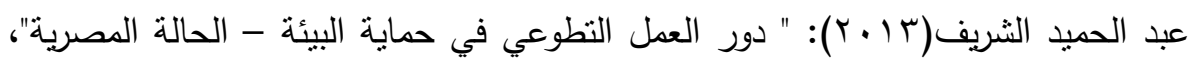

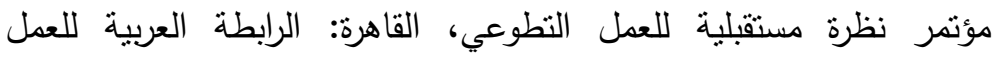

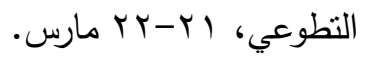

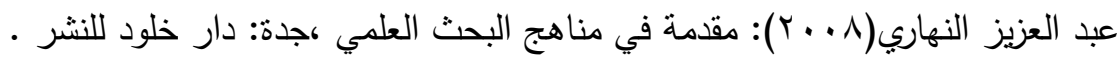

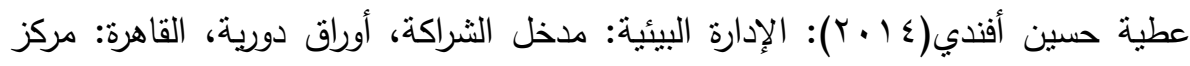
دراسات الإدارة العامة كلية الاقتصاد والعلوم السياسية - جامعة القاهرة.

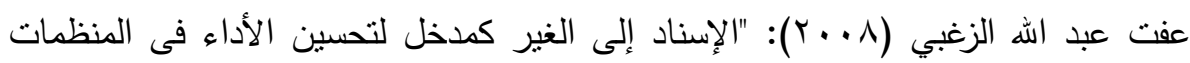

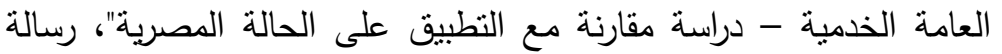

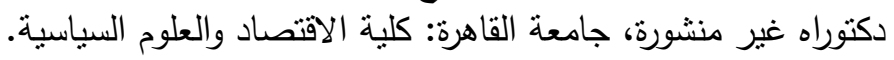

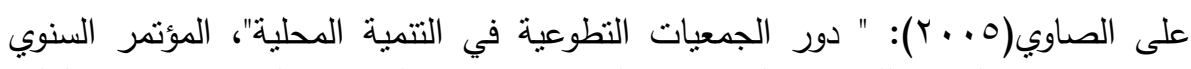

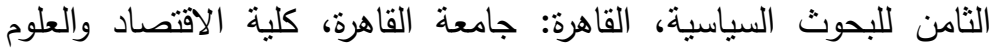

السياسية، مركز البحوث والدراسات السياسية، ب-ه ديسمبة الفهر،

$$
\text { المجلد السابع والثلاثون، الجزء الثاني، مارس Y Y r r }
$$




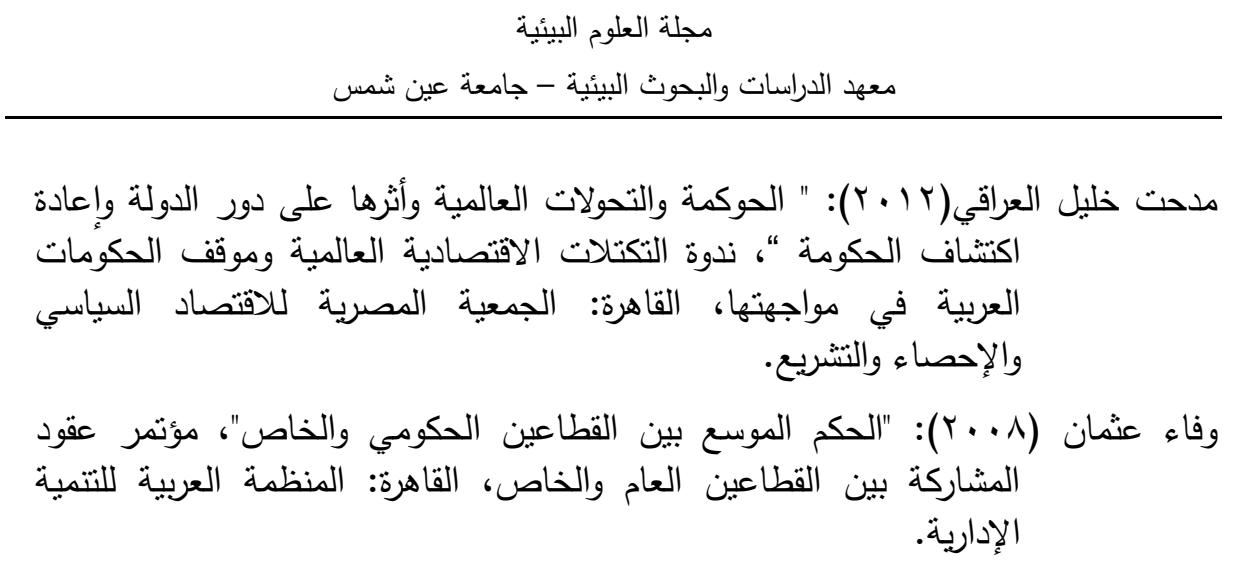

Dean, Mitchell (1999), Governmentality, Power and Rule in Modern Society, USA: California, SAGE Publications, Inc.

Durley,W.(2013), Thinking about thinking: Managing :The New Public Services, USA, New Jersey , Columbus , Merrill publishing company.

Hukme, D.(2006), Governance, Administrate and Development - Make the State Work, London: Macmillan Press Ltd.

Farnham, D. and Horton, S (2009), Managing the New Public Services, $2^{\text {nd }}$ Ed. London: Macmillan Press Ltd.

Fisher, R.(2011), Decentralizing Environment Management (London: Macmillan Press Ltd.

Gerry, S. (2014), The New Management of British Local_Governance, London: Macmillan Press Ltd.

Nicolas, Sr. (2012). Redefining the State - Privatization and Welfare Reform, UK: Cambridge University Press.

Osborne, David and Gaebler, Ted,(1992). Reinventing Government, How the Entrepreneurial Spirit is Transforming the Public Sector, USA: New York, Addison Wesley Publishing Co., Inc.

Saves, E. S.(2011): Privatization - The Key to Better Government, USA: Chatham House Publisher, Inc.. 
UNDP (2003), Local Participatory Development, Egypt Human Development Report , Cairo : Institute of National Planning.

UNDP (2011), The Shrinking State: Governance and Human Development of Independent States, Regional Bureau for Europe .N.Y.

\title{
THE ELEMENTS OF THE APPLICATION OF THE EXPANDED RULE AS AN INPUT TO IMPROVE THE ENVIRONMENTAL SITUATION IN EGYPT - AN EMPIRICAL STUDY
}

\author{
Sobh, M. A. ${ }^{(1)}$; Shahata, Nihal, F.M. ${ }^{(2)}$; Hussain, A. ${ }^{(3)}$
} and Noman, A. M. ${ }^{(4)}$

1) Faculty of Commerce, Ain Shams University 2) Institute of Environmental Studies and Research, Ain Shams University 3) the Egyptian Environmental Affairs Agency 4) Sadat Academy for Management Sciences.

\begin{abstract}
The research aims to study the concept of Environmental Governance and dimensions and effervescence and analysis of environmental government policies toward activating the participation of non-governmental organizations in carrying out environmental activities and display the evolution of the state's role in the performance of environmental activism, and the quality of environmental activities focusing on the Cairo governorate.

The researcher used the Descriptive Analytical Method for this purpose, and use the survey as a key tool to collect data, it amounted to community size of 250 single, and the size of the sample of 152 single and was a random sample was used statistical software package

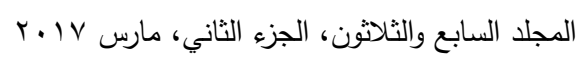




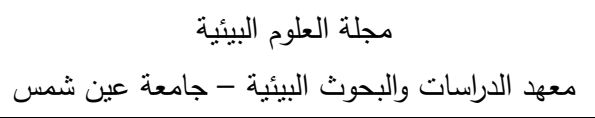

(Statistical Package for Social Science) SPSS for entry, processing and analysis of data.

The Result: No statistically significant relationship at the level of $\leq$ ( $\alpha 0.05$ ) between the availability of the elements of the expanded rule between the government and non-governmental organizations and partnership in improving the environmental situation in Egypt.

The Recommendations: The study concluded to provide several recommendations for the application of the enlarged to improve the environmental situation of governance through enhancing the participation of non-governmental organizations in the fields of environmental protection, which included the need to develop the legislative framework and coordinating supported the relationship between the government and non-governmental organizations and the opportunity for the participation of non-governmental organizations in set priorities for environmental work and contribute to environmental policy-making, and benefit from the comparative advantages of nongovernmental organizations and the need to legalize the funding situation for NGOs and organize supervisory relationship on foreign funding to NGOs. 